\title{
WestVirginiaUniversity
}

THE RESEARCH REPOSITORY @ WVU

Graduate Theses, Dissertations, and Problem Reports

2013

\section{The Influence of Gender on the Peer Leadership-Cohesion Relationship}

Michael E. Berrebi

West Virginia University

Follow this and additional works at: https://researchrepository.wvu.edu/etd

\section{Recommended Citation}

Berrebi, Michael E., "The Influence of Gender on the Peer Leadership-Cohesion Relationship" (2013). Graduate Theses, Dissertations, and Problem Reports. 647.

https://researchrepository.wvu.edu/etd/647

This Thesis is protected by copyright and/or related rights. It has been brought to you by the The Research Repository @ WVU with permission from the rights-holder(s). You are free to use this Thesis in any way that is permitted by the copyright and related rights legislation that applies to your use. For other uses you must obtain permission from the rights-holder(s) directly, unless additional rights are indicated by a Creative Commons license in the record and/ or on the work itself. This Thesis has been accepted for inclusion in WVU Graduate Theses, Dissertations, and Problem Reports collection by an authorized administrator of The Research Repository @ WVU. For more information, please contact researchrepository@mail.wvu.edu. 
The Influence of Gender on the Peer Leadership-Cohesion Relationship

Michael E. Berrebi, B.S.

Thesis submitted to the College of Physical Activity and Sport Sciences at West Virginia University

in partial fulfillment of the requirements for the degree of

Master of Science in Sport \& Exercise Psychology

\author{
Edward Etzel, Ed.D., Chair \\ Vanessa Shannon, Ph.D. \\ Ed Jacobs, Ph.D.
}

Department of Sport Sciences

Morgantown, WV

2013

Keywords: cohesion, peer leadership, athlete leadership, college athletes, soccer Copyright 2013 Michael E. Berrebi 


\section{ABSTRACT \\ The Influence of Gender on the Peer Leadership-Cohesion Relationship}

\section{Michael E. Berrebi}

Research shows that a moderate to large cohesion-performance relationship exists, suggesting teams that build strong social and task cohesion are more likely to be successful. This effect has also found to be stronger in female over male teams. Peer leadership positions are somewhat overshadowed by coach positions on sport teams but can have an important influence on a team's task and social cohesion. This study investigated the influence gender has on the peer leadership-cohesion relationship. Participants were 381 NCAA Division I male and female soccer players from 67 different universities. Each participant completed questionnaires assessing team cohesion and athlete leader behaviors. Overall, it was found that for both male and females, all four cohesion dimensions were positively related to the leadership behaviors of Democratic Behavior, Training and Instruction, Social Support, and Positive Feedback. Specifically for males, Autocratic Behavior was a strong predictor of two cohesion dimensions. For females, Social Support was a significant predictor of all four cohesion dimensions. These findings provide researchers, coaches, and sport psychology consultants evidence that male and female athlete leaders may influence team cohesion in different ways, and it is important to develop athlete leaders behaviors on male and female sport teams that are more effective at strengthening both task and social cohesion in order to also improve performance. 


\section{ACKNOWLEDGEMENTS}

I would like to first thank my advisor and Committee Chair, Dr. Edward Etzel, for all of his support and feedback during this long (but rewarding) thesis experience.

I would also like to thank the other two members of my committee for their help and feedback, Dr. Ed Jacobs and Dr. Vanessa Shannon. I want to specifically thank Dr. Shannon for all of her time and assistance during the early stages of this project, as well as for all of her support while analyzing my data and trying to figure out what exactly it all means.

Thank you to the rest of the faculty and students in the WVU Sport \& Exercise Psychology program for their support, especially my fellow cohort member Leigh Bryant for her encouragement, positivity, and friendship since day one. I also want to thank my roommate Pete Kadushin for helping me to see the light at the end of the tunnel at crucial times during this process.

Last but certainly not least, thank you to my parents, brothers, and wonderful fiancé for their unwavering love and support both in the thesis process and in life. 


\section{TABLE OF CONTENTS}

Page \#

Introduction $\quad 1$

$\begin{array}{ll}\text { Methods } & 7\end{array}$

$\begin{array}{ll}\text { Participants } & 7\end{array}$

$\begin{array}{ll}\text { Research Design } & 7\end{array}$

$\begin{array}{ll}\text { Instrumentation } & 8\end{array}$

$\begin{array}{ll}\text { Demographic questionnaire } & 8\end{array}$

$\begin{array}{ll}\text { Cohesion } & 8\end{array}$

$\begin{array}{ll}\text { Peer leadership behaviors } & 9\end{array}$

$\begin{array}{ll}\text { Procedure } & 10\end{array}$

$\begin{array}{ll}\text { Data Analysis } & 12\end{array}$

$\begin{array}{ll}\text { Results } & 13\end{array}$

$\begin{array}{ll}\text { Descriptive Statistics } & 13\end{array}$

$\begin{array}{ll}\text { Multiple Regressions } & 14\end{array}$

$\begin{array}{ll}\text { Discussion } & 15\end{array}$

Comparing Results with Previous Literature 15

$\begin{array}{ll}\text { Gender Differences } & 19\end{array}$

$\begin{array}{ll}\text { Limitations } & 21\end{array}$

Practical Implications and Future Research $\quad 22$

$\begin{array}{ll}\text { References } & 25\end{array}$

$\begin{array}{ll}\text { Appendices } & 28\end{array}$

Appendix A: Sample Head Coach Letter 29 
Appendix B: Sample Participant Cover Letter

Appendix C: Sample Demographic Questionnaire 


\section{Introduction}

It is logical to think that many of the best sport teams are not only unified socially but also united in meeting all of the team's established goals. In the field of sport psychology, this type of team would be regarded as having a high degree of cohesion, commonly defined as "a dynamic process which is reflected in the tendency for a group to stick together and remain united in the pursuit of its instrumental objectives and/or the satisfaction of member affective needs" (Carron, Brawley, \& Widmeyer, 1998, p. 213). This definition is important because it highlights the potential for both a social and task construct of cohesion, as well as the need to understand cohesion both at a group level and related to the perceptions of individual team members. An important question to consider in regards to the nature of cohesion is whether or not a cohesion-performance actually exists. In other words, do cohesive teams actually perform better than non-cohesive teams? Furthermore, which is more essential for team success, a team that gets along well socially or a team that is cohesive around the team's task objectives?

The most comprehensive evidence for the existence of a cohesion-performance relationship is a meta-analysis that evaluated 46 studies containing 164 effect sizes on the cohesion-performance relationship in sport. In this meta-analysis, Carron, Colman, Wheeler, and Stevens (2002) found that there is a significant moderate to large cohesion-performance relationship. In addition, performance was found to be more strongly related to social cohesion than task cohesion. This finding suggests that developing social cohesion on a sport team may be more important for performance than developing task cohesion around specific tasks. Researchers also indicated that female athletic teams were characterized by a significantly stronger cohesion-performance effect than male teams. Based on the findings of the meta- 
analysis, it would seem that female teams might be more vulnerable than male teams to performance issues when the cohesion of the team is compromised.

Since evidence exists that cohesion is related to performance, it would also seem useful to identify what factors may influence cohesion on sport teams. Carron and Hausenblas (1998) originally identified these factors that include: environmental, personal, team, or leadership factors. An example of an environmental factor is how many team members are actually a part of the team. Competitive trait anxiety or personal investments are both examples of personal factors. Team factors might include role clarity or group norms. Finally, a leadership factor might be the leader's decision-making style. It is suggested that these four factors are dynamically interrelated and interact in the development of cohesion on sport teams.

One factor that may influence cohesion that is especially important in the proposed study is leadership. Leadership has been defined many times in different disciplines but will be defined here as "a process whereby an individual influences a group of individuals to achieve a common goal" (Northouse, 2001, p. 3). Since coaches are the traditional leaders of most teams, it appears important to understand what type of leadership behaviors athletes prefer their coaches to display. Early research identified differences between male and female athletes' preferred coach leadership style. For example, research on Canadian physical education majors found that male students preferred more Autocratic Behavior and Social Support than female students who preferred Democratic Behavior (Chelladurai \& Saleh, 1978). This finding has been confirmed by more recent supplementary research on 408 Division I and II North American student-athletes that found similar leadership preferences, as well as the finding that some females preferred Training and Instruction behaviors (Beam, Serwatka, \& Wilson, 2004). Beam et al. found no significant differences in preferred leadership behaviors among competition level. 
It is evident that leadership is an important factor in the development of cohesion. Furthermore, it is known that a moderate to strong cohesion-performance relationship exists in sport. Therefore, leadership is an important factor to examine in regards to its effect on the cohesion and overall performance of a team. Currently, there is a wealth of research on coaching leadership and its effect on the cohesion (Gardner, Shields, Bredemeier, \& Bostrom, 1996; Jowett \& Chaundy, 2004; Murray, 2006; Pease \& Kozub, 1994). This research has found a positive relationship exists between task cohesion and the leadership dimensions of Training and Instruction, Social Support, Positive Feedback, and Democratic behavior. Other research has produced similar results but also suggests that style is negatively related to cohesion (e.g., Shields, Gardner, Bredemeier, \& Bostro, 1997).

These types of studies depicting the coach as the leader are pervasive throughout the sport psychology literature. However, athletes (or peers) serving in leadership roles have not been examined to the same extent. Early researchers suggested that peer leaders are an essential part of athletic success on the field (Gould, Hodge, Peterson, \& Petlichkoff, 1987). These peer leaders have also been found to serve both formal (e.g., designated team captain) and informal (e.g., physical enforcer) roles on sport teams. Peer leaders have found to serve both social and task leadership roles (Loughead, Hardy, \& Eys, 2006). Other research suggests that up to 25\% of the athletes on teams serve in leadership roles and display different behaviors than coach leaders. For example, both elite high school soccer players and Canadian university athletes serving as peer leaders have been found to exhibit more Social Support, Positive Feedback, and Democratic Behavior versus coaches that tended to display more Autocratic Behavior and Training and Instruction (Glenn, Horn, \& Campbell, 2010; Loughead \& Hardy, 2005). The 
importance of these findings seems to be that peer leadership may not be directly equivalent to coach leadership, both in the number of leaders on a team and the type of behaviors exhibited.

Little research has looked at the relationship between peer leadership behaviors and cohesion, despite the number of studies that have featured the coach as a leader. This is somewhat puzzling especially since research has suggested that peer leaders play an important part in determining how team members perceive the cohesion of the team (Price \& Weiss, 2011). Only a few studies have explored the relationship between peer leadership style and cohesion. For example, Dupuis, Bloom, and Loughead (2006) used semi-structured interviews to explore six former Canadian ice hockey captains' perceptions of peer leadership. Although the researchers were not studying specific leadership behaviors, it was observed that these male captains tried to foster cohesion in the team by using a more participatory (or democratic) leadership style.

Although Dupuis et al. (2006) were able to report that athlete leaders engaged in leadership behaviors that attempted to enhance team cohesion, it should be noted that the researchers were unable to specify these particular leadership behaviors (e.g., Democratic Behavior or Positive Feedback). Therefore, Vincer and Loughead (2010) were the first researchers to explore the peer leadership-cohesion relationship in a quantitative manner. The researchers accomplished this by examining the relationship with over 300 Canadian varsity and club athletes in various interactive sports. Using the Group Environment Questionnaire (GEQ; Carron, Brawley, \& Widmeyer, 1985) and a modified version of the Leadership Scale for Sports (Chelladurai \& Saleh, 1980) in which item stems of "coach" were changed to "peer leader", the researchers found that the leadership behaviors of Training and Instruction and Social Support positively influenced all four constructs of team cohesion. Autocratic Behavior was negatively 
associated with perceived cohesion. Interestingly, Democratic Behavior was only positively associated with the ATG-T cohesion subscale.

In this important study, Vincer and Loughead (2010) used a novel means to investigate the peer leadership-cohesion relationship. The researchers suggested for future research to use the foundation of Multidimensional Model of Leadership (MML) theory to further explore this relationship with regards to other leadership characteristics that may influence team cohesion and member satisfaction, such as gender. In the sport psychology literature, some research has suggested a gender difference in preferred leadership, while other research has produced results that do not match earlier findings. For example, Sherman, Fuller, and Speed (2000) found that within single and dual-gender Australian sport teams, athletes of all sports and gender preferred Positive Feedback, Training and Instruction, and Democratic Behaviors. Female athletes reported a slightly greater preference for democratic style but, in general, gender did not seem to be an important factor in preferred leadership style. Overall, it seems unclear whether male or female athletes prefer different leadership behaviors. In addition, differences in the leadershipcohesion relationship between male and female athletes have not yet been studied

Recently, Loughead and Hardy (2005) found that peer leaders demonstrate more constructive leadership behaviors than coaches, such as Social Support, Positive Feedback, and Democratic Behavior. Despite this knowledge, little research has been conducted on how peer leadership affects cohesion (e.g., Vincer \& Loughead, 2010). With this knowledge, effective peer leaders would ideally be able to lead their teams while fostering team cohesion, resulting in consistent, high-quality performances. Although some research has shown that coaching leadership influences team cohesion (e.g., Murray, 2006), little research has been conducted on peer leadership and its influence on team cohesion (e.g., Vincer \& Loughead, 2010). Although it 
has been suggested that athlete gender may mediate the relationship between cohesion and performance (Carron et al., 2002), it remains unclear whether leadership behavior influences perceived cohesion with respect to gender. Therefore, it is important to examine the potential impact of gender on the relationship between athlete leader behaviors and cohesion.

This main purpose of this study was to investigate the way in which peer leadership behaviors influence perceived cohesion with respect to gender. Based on the modest literature on the peer leadership-cohesion relationship, the researcher proposed two hypotheses: First, it was hypothesized that the leadership dimensions of Democratic Behavior, Social Support, and Positive Feedback would have a stronger, more positive influence on all four dimensions of cohesion in females compared to males. Second, it was also hypothesized that the leadership dimensions of Autocratic Behavior and Training and Instruction would have a stronger, more positive influence all four dimensions of cohesion in males compared to females.

Some research has shown there are differences between male and female preferred leadership styles (Beam et al., 2004), but it is unclear if there are differences between male and female athletes in how peer leadership style influences cohesion. If the impact of gender on the athlete leadership-cohesion relationship is better understood, coaches of both male and female teams could better educate their athlete leaders (e.g., team captains) in ways that could effectively promote cohesion. Furthermore, sport psychology consultants who are helping to address leadership problems on teams could use guidance to help promote effective leadership skills suited to their particular type of team. 


\section{Methods}

\section{Participants}

Participants were 381 NCAA Division I soccer players (247 females and 134 males) from 67 different universities in the United States. The mean age of all participants was 19.77 years $(\mathrm{SD}=1.30)$. The majority of participants were freshmen $(33.1 \%)$, with remaining participants being sophomores (28.6\%), juniors (22.6\%), seniors (15.2\%), and graduate students (.5\%). 207 players reported having a partial scholarship (54.6\%), while 96 reported having no scholarship (25.3\%), and 76 players reported having a full scholarship $(20.1 \%)$. The majority of players $(59.2 \%)$ reported being starters, while the remaining reported being non-starters $(40.8 \%)$. For race/ethnicity, the majority of participants were white/Caucasian $(80.3 \%)$. The rest of the participants reported being among six other commonly reported race/ethnicities. The gender of the participants' coaches was predominately male (74.9\%), as opposed to female $(25.1 \%)$. The vast majority of participants did not report being injured $(83.6 \%)$ during the data collection process.

\section{Research Design}

This study was correlational in nature and utilized a quantitative approach to investigate if gender influenced the peer leadership-cohesion relationship. The researcher used a purposive sample to recruit participants that met the inclusion criteria for the study. Participants filled out two questionnaires based on perceptions of their peer leaders' behaviors and overall team cohesion. The study used a multiple stepwise regression analysis, as well as a number of descriptive statistical analyses to investigate the hypotheses. 


\section{Instrumentation}

Demographic questionnaire. The researcher used a self-constructed demographic survey (see Appendix C) to gather the following information: age, gender, gender of coach, school of enrollment, race/ethnicity, year in school, contractual obligation, status (i.e., starter vs. non-starter), and win-loss record. Identifying information such as school of enrollment was collected to help determine how many participants from a particular university had completed the surveys. The researcher sampled all participants during the early spring offseason in order to obtain more responses and prevent biases from perceptions of team cohesion related to current team success.

Cohesion. The Group Environment Questionnaire (GEQ; Carron, Widmeyer, \& Brawley, 1985) is an 18-item questionnaire that was used to assess perceptions of cohesion among athletic teams (see Appendix D). The GEQ assesses perceptions of cohesion using the four dimensions of cohesion that include ATG-S (5 items), ATG-T (4 items), GI-S (4 items), and GI-T (5 items). The ATG-S subscale assesses how attractive the group is to the individual on a social and friendship level. The ATG-T subscale assesses the individual's attraction to the group's goals, responsibilities, and tasks. The GI-S subscale of the GEQ assesses an individual group member's perception of the social harmony and closeness within the group. Finally, the GI-T subscale assesses a team member's opinion of the degree of task unity within the group as a whole. An example of an item from the ATG-S subscale is: For me, this team is one of the most important social groups to which I belong. An example of an item from the ATG-T subscale is: I'm unhappy with my team's level of desire to win. An example of an item from the GI-S subscale is: Members of our team do not stick together outside of practice and games. Finally, an example from the GI-T subscale is: We all take responsibility for any loss or poor 
performance by our team. All items were rated on a Likert-type scale from 1 (strongly disagree) to 9 (strongly agree). To score the GEQ, each factor is summed and an average score is taken for the individual athlete and the team as a whole. A number of items throughout the GEQ must also be reverse scored. Research has shown the GEQ to exhibit adequate psychometric properties. The first actual publication of the GEQ confirmed the content validity of the instrument (Carron et al., 1985). The GEQ has also been shown to have predictive validity and adequate concurrent validity when compared to other similar instruments such as the SCQ (Brawley, Carron, \& Widmeyer, 1987). Furthermore, in use with collegiate athletes, the GEQ has demonstrated acceptable internal consistency reliabilities for the four cohesion subscales. These Cronbach alphas include: ATG-T $(\alpha=.65)$, ATG-S $(\alpha=.60)$, GI-T $(\alpha=.71)$, and GI-S $(\alpha=.72$; Vincer $\&$ Loughead, 2010). These values fall within the generally accepted reliability levels as determined by Nunnally \& Bernstein (1994). The instrument has been used in a wide variety of studies to assess cohesion in collegiate athletes (e.g., Gardner, Shields, Bredemeier, \& Bostrom, 1996; Jowett \& Chaundy, 2004).

Peer leadership behaviors. A modified version of the Leadership Scale for Sports (Chelladurai \& Saleh, 1980) was used to assess athlete leadership (see Appendix E). Loughead and Hardy (2005) were the first researchers to use this version of the LSS to assess athlete (as opposed to coach) leadership by simply changing the stems of "my coach..." to "my peer leader(s)..." for all items. The modified LSS uses 40 items to measure the same five dimensions of leadership behavior: 1) Training and Instruction- (13 items); 2) Democratic Behavior- (9 items); 3) Autocratic Behavior- (5 items); 4) Social Support- (8 items); and 5) Positive Feedback- (5 items). Items on the five dimensions of leadership behaviors are scored on a Likert-type scale from 1 (never) to 5 (always) regarding statements about the peer leader(s) on 
the team. To score the modified LSS, items are summed to get a total score for each of the five leadership dimensions. This total score is then divided by the number of items per leadership dimension to get a final score out of five. The five leadership dimensions were originally proposed to reflect the five most important aspects in regards to coach leadership. Research on coach leadership style has shown that all of these dimensions except Autocratic Behavior were positively related to task and social cohesion (e.g., Nezhad \& Keshtan, 2010; Westre \& Weiss, 1991). Chelladurai and Saleh (1980) showed both the preferred and perceived versions of the LSS to have satisfactory content and factorial validity as well as adequate internal consistency reliabilities for the five leadership subscales. More recently, Vincer and Loughead (2010) found acceptable internal consistency reliabilities for the modified LSS dimensions when used with collegiate athletes. These reliability scores included: Training and Instruction $(\alpha=.88)$, Democratic Behavior $(\alpha=.79)$, Autocratic Behavior $(\alpha=.74)$, Social Support $(\alpha=.86)$, and Positive Feedback $(\alpha=.84)$. These Cronbach alpha values fall within the accepted reliability levels as determined by Nunnally \& Bernstein (1994). Since its inception as a tool to measure leadership behaviors on sport teams, the LSS has been successfully used in many studies looking at coaching leadership (e.g., Chelladurai \& Carron, 1983; Murray, 2006). A few studies have also used the LSS, RLSS, or a modified version of the LSS to investigate athlete leadership (e.g., Beam et al., 2004; Loughead \& Hardy, 2005; Vincer \& Loughead, 2010).

\section{Procedure}

After receiving permission from the university's institutional review board, all NCAA Division I male and female head soccer coaches were contacted via email (see Appendix A) to explain the study and request participation of the athletes on their teams. Coaches were informed that participation in the study would give them access to the overall findings of the study once 
the researcher had compiled and analyzed all data. Additional links to leadership and cohesion resources were offered for participation in the study. Coaches were asked to forward the survey link from www.surveymonkey.com on to their players if they agreed to allow participation. Due to an error with the initial survey link, all head coaches were contacted two weeks after the initial email with a new working link to the questionnaires. Subsequently, follow-up emails were sent to all coaches every two weeks for six total weeks.

Overall, 23 male coaches (11.6\%) and 35 female coaches (11.1\%) responded and agreed to pass on the survey link. After the initial data collection phase, the number of male participants was adjudged to be too few to have adequate power for the necessary statistical analyses. Therefore, after again obtaining IRB approval, a second data collection was initiated that involved contacting individual male players. The researcher contacted all players from teams that featured a head coach who had already agreed to forward on the study. Player email addresses were obtained using university public directories. Players were informed that their head coach had agreed to forward on the study, and if possible to take the time to fill out the surveys.

All participants who opened the survey link first saw an informative cover letter (see Appendix B) detailing the purpose of the study and explaining participant rights. These rights included the ability to end participation in the study at any point with no consequences. There was also an option to print a copy of the cover letter for personal records. If participants wished to continue, they next filled out a page of basic demographic information. After the demographic information was completed, participants completed online versions of both the cohesion and peer leadership scales. Successful completion of the demographic information and two questionnaires was predicted to take approximately twenty minutes. The order of the 
questionnaire items were randomized for both scales. Finally, the participants received the primary researcher's contact information so that participants could communicate with the researcher about any issues related to the collection procedures.

Data collection began early in the spring offseason. This was done to increase the probability of obtaining a large enough sample size. Attempting to sample during the competitive fall season may have prevented coaches from allowing the athletes on their teams from participating in the study. This time period also helped limit any biases occurring from differences in cohesion due to issues that may have surfaced during the season (e.g., a recent bad loss to rival team or a key player suffering a season-ending injury). Collecting data at this time also helped avoid bias due to perceived cohesion being influenced by a team's win-loss record at the time of sampling.

\section{Data Analysis}

Data analysis included both descriptive (e.g., frequencies, correlations, measures of central tendency, and standard deviations) and inferential statistical tests (e.g., regression analyses) to investigate the hypotheses. All collected data was cleaned in Microsoft Excel and entered into the Statistical Package for Social Sciences version 21 (SPSS). Items were appropriately reverse-scored and any participant that did not fill out at least the majority of items from either the LSS or GEQ was eliminated from the final aggregate. A basic demographic questionnaire was used to investigate participant characteristics such as age, gender, race/ethnicity, gender of coach, and year on team. Frequencies, means, standard deviations, and other descriptive data were calculated for this demographic information. Overall means and standard deviations were also calculated for all cohesion and peer leadership behavior dimensions. The four cohesion constructs were not combined, as it has been suggested that this 
is inappropriate due to each of the constructs being conceptually different and having different antecedents (Brawley, Carron, \& Widmeyer, 2002). The relationships between the independent and dependent variables were also examined using bivariate correlational analyses and multiple stepwise regressions. For correlations, all dimensions of cohesion and the five peer leadership behaviors were run in a correlational matrix to examine the strength of the relationship between the variables. This was completed for both male and female data to compare correlation strengths between genders. For both male and female participants, the five peer leadership dimensions were used as predictors in a stepwise regression for each of the four cohesion dimensions.

\section{Results}

\section{Descriptive Statistics}

Means and standard deviations were calculated for all four dimensions of cohesion and the five peer leadership behaviors. These statistics were analyzed across all participants and specifically by gender (see Table 1). Overall, the highest-rated cohesion dimension was Individual Attractions to the Group-Social $(\mathrm{M}=7.49, \mathrm{SD}=1.45)$. The lowest-rated cohesion dimension was Group Integration-Task $(\mathrm{M}=6.66, \mathrm{SD}=1.57)$. For peer leadership, the highestrated behavior was Positive Feedback $(\mathrm{M}=4.11, \mathrm{SD}=.85)$, while the lowest-rated leadership behavior was Autocratic Behavior $(\mathrm{M}=2.40, \mathrm{SD}=.81)$. For male participants, the highest-rated cohesion dimension was Individual Attractions to the Group-Social $(\mathrm{M}=7.38, \mathrm{SD}=1.46)$ and the highest-rated peer leadership behavior was Positive Feedback $(\mathrm{M}=4.17, \mathrm{SD}=.73)$. For females, the highest-rated cohesion dimension was also Individual Attractions to the GroupSocial $(\mathrm{M}=7.54, \mathrm{SD}=1.44)$. The highest-rated peer leadership behavior was Positive Feedback $(\mathrm{M}=4.09, \mathrm{SD}=.91)$. 
Bivariate correlations for both males and females were calculated for all mean scores of the cohesion and peer leadership subscales. A summary of these correlations can be found in Table 2, which shows that a statistically significant relationship exists between all of the variables in the study. Specifically, for males and females the four cohesion dimensions of Individual Attractions to the Group-Task, Individual Attractions to the Group-social, Group Integration-Task, and Group Integration-Social were all positively related to the peer leadership behaviors of Training and Instruction, Democratic Behavior, Social Support, and Positive Feedback. In contrast, for both males and females the four cohesion dimensions were negatively related to the peer leadership behavior of Autocratic Behavior. When comparing across gender, the largest correlational difference was between the Social Support peer leadership and the cohesion dimension of Group Integration-Task.

\section{Multiple Regressions}

Four stepwise regressions were used to determine the influence of peer leadership behaviors on task and social cohesion for both males and females. In the regressions, the five peer leadership behaviors served as independent variables and the four cohesion dimensions served as dependent variables. The results of the stepwise regressions are found in Table 3, which shows that for male participants, it was found that the peer leadership behavior of Training and Instruction was a significant predictor of the cohesion dimensions of Individual Attractions to the Group-Task, Group Integration-Task, and Group Integration-Social. The Autocratic Behavior peer leadership behavior was a significant predictor of Individual Attractions to the Group-Social and Group Integration-Task dimensions. Alternatively, Democratic behavior was a significant predictor of both the Individual Attractions to the Group-Task and Individual 
Attractions to the Group-Social dimension. The Positive Feedback peer leadership behavior was a significant predictor of the Group Integration-Social cohesion dimension.

Table 3 also shows that for female participants, the Social support peer leadership behavior was found to be a significant predictor of all four cohesion dimensions. The Training and Instruction peer leadership behavior was found to be a significant predictor of Individual Attractions to the Group-Task, Group Integration-Task, and Group Integration-Social. The peer leadership behaviors of Autocratic Behavior and Democratic Behavior were both found to be significant predictors of only the Group Integration-Task cohesion dimension. When analyzing across male and female data, the Training and Instruction peer leadership behavior was found to be a significant predictor of all cohesion dimensions except Individual Attractions to the GroupSocial. For females, the Social Support peer leadership behavior was found to be a significant predictor of all four cohesion dimensions.

\section{Discussion}

\section{Comparing Results with Previous Literature}

This study examined the influence of gender on the peer leadership-cohesion relationship. Participants completed the Group Environment Questionnaire and a modified version of the Leadership Scale for Sports that assessed perceptions of cohesion and their peer leader behaviors, respectively. Stepwise regressions and bivariate correlations were used to determine differences between male and female participants in how the five peer leader behaviors influenced both task and social cohesion. Overall, participants perceived higher social (Individual Attractions to the Group-Social, Group Integration-Social) cohesion than task (Individual Attractions to the Group-Task, Group Integration-Task) cohesion on their teams. Furthermore, participants rated their athlete leaders as demonstrating a higher amount of Positive 
Feedback and Social Support, as well as less Democratic and Autocratic Behavior. It was also found that across gender, the peer leader behaviors of Positive Feedback, Social Support, Training and Instruction, and Democratic Behavior were all found to be positively related to task and social cohesion. Autocratic peer leader behavior was found to be negatively related to all four cohesion dimensions.

It was hypothesized that the Social Support, Positive Feedback, and Democratic peer leader behaviors would more positively influence all four cohesion dimensions in females. This hypothesis was partially supported as it was found that for female participants, the Social Support peer leader behavior was found to be a significant predictor of all four cohesion dimensions. However, when stepwise regressions were run for male participants, the Social Support peer leader behavior was not found to be a significant predictor of any of the four cohesion dimensions. In addition, correlational analysis showed that Social Support (as well as Positive Feedback) was more positively associated with social cohesion and the Group Integration-Task dimension. These findings support the prediction that it is more important for female athlete leaders to provide social acceptance and helpful feedback to their teammates to promote better task and social cohesion.

It was also hypothesized that the peer leader behaviors of Training and Instruction and Autocratic Behavior would have more of an influence on all four cohesion dimensions in males than females. This second hypothesis was partially supported as it was found that Autocratic peer leader behavior was a significant predictor of Individual Attractions to the Group-Social and Group Integration-Task cohesion dimensions in males but only the Group Integration-Task dimension in females. This finding indicates that for males, peer leaders who take more control over team decisions have an impact on how closely individuals felt to the team on a social level. 
It is possible that when one or two athlete leaders makes the decisions, it is easier for the rest of the team to accept the decision and focus more on the social aspect that is enjoyable about the team. This could be explained by the idea of leadership dispersion, put forth by Neubert (1999). Essentially, situations could arise where there are too many individuals trying to make a decision, which could hinder effective communication and a decrease the sense of social unity on the team.

Training and Instruction peer leader behavior was found to be a significant predictor of task cohesion and the Group Integration-Social cohesion dimension for both males and females. In early research on leadership preferences, Chelladurai (1983) found that more experienced athletes prefer more Training and Instruction from coaches than less experienced athletes. Other researchers found that college coaches displayed more Training and Instruction compared to high school or junior high school coaches. It was suggested that college coaches have more time to devote to this type of coaching and success at this level is more determined by their own training methods (Jambor \& Zhang, 1997). Researchers have also found that team captains tend to adopt a leadership style similar to the one of their coach (Dupuis et al., 2006). Therefore, at the Division I level of collegiate soccer, it is intuitive that both male and female peer leaders exhibit more Training and Instruction behavior that could influence team cohesion.

Correlational analysis confirmed the findings of a number of previous research studies investigating the relationship between cohesion and leadership. For example, the finding that Positive Feedback, Social Support, Training and Instruction, and Democratic peer leader behaviors were all positively related and Autocratic Behavior was negatively related to task and social cohesion agrees with previous research on coach (e.g., Jowett \& Chaundy, 2004; Nezhad \& Keshtan, 2010; Shield et al., 1997) and athlete (Dupuis et al., 2006; Vincer \& Loughead, 
2010) leadership. Clearly, both male and female athletes perceive that receiving encouragement, specific performance instruction, social acceptance and interaction, and a voice in team decisions and goals increases the overall task and social cohesion. This is the case whether the leader is a coach or athlete. On the other hand, having a leader who takes sole responsibility for team decisions and does not take into account the group's opinions can have a negative influence on task and social cohesion. Therefore, it is crucial for athlete leaders, regardless of whether they are designated formal leaders (e.g., captains) or merely informal leaders, to take into account their teammates thoughts and feelings when coming to decisions on team issues, goals, or objectives.

Previous literature has suggested that peer leaders play a crucial part in determining how other team members perceive team chemistry (Price \& Weiss, 2011). However, few studies have looked specifically at the influence of peer leadership on perceived cohesion at the collegiate level. The findings of this study are consistent with research that found ice hockey captains who were perceived as using a democratic style facilitated increased team cohesion (Dupuis et al., 2006). Furthermore, the only other known study to investigate how athlete leadership influences team cohesion showed that Training and Instruction and Social Support peer leader behaviors were positively related to both task and social cohesion and Autocratic Behavior was negatively related to all four cohesion dimensions (Vincer \& Loughead, 2010). In this study, Positive Feedback and Democratic peer leader behaviors were also positively related to all four cohesion dimensions. This finding reflects previous research by Loughead and Hardy (2005) that found athlete leaders from a variety of team sports exhibit more Social Support, Positive Feedback, and Democratic Behavior than coaches. It is also possible that Positive Feedback and Democratic Behavior is more vital in the sport of soccer. In such a highly coordinated, large-team sport, 
receiving consistent encouragement and appreciation for one's effort and creating a democratic, team-based atmosphere about decisions and goals may have a stronger overall influence on team cohesion.

\section{Gender Differences}

As mentioned previously, there is lack of research on gender differences in the peer leadership-cohesion relationship. Analyzing these results revealed several important findings related to how gender might impact the relationship between peer leader behaviors and team cohesion. For example, a somewhat surprising result of this study is that for both males and females, the Training and Instruction peer leader behavior is a significant predictor of all cohesion dimensions except Individual Attractions to the Group-Social. Previous research has shown that male athletes prefer Autocratic and Social Support behaviors from their coaches, while females prefer Training and Instruction (Beam et al., 2004). The findings of this study suggests that athletes may prefer for peer leaders to exhibit Training and Instruction behavior more than their coaches, which can have a significant influence on task cohesion and the group's perception of the team's social cohesion. Therefore, both male and female athlete leaders should seek to provide specific feedback to help improve their teammates skills, as this may improve the team's task cohesion. This is the case even if the coach is traditionally in charge of this role.

This study had several novel findings regarding differences between male and female peer leaders and how their behaviors influence cohesion. Arguably the most substantial finding of this study was that for females, Social Support was found to be a significant predictor of all four cohesion dimensions. Alternatively, Social Support was not found to be a significant predictor of any of the four cohesion dimensions in males. Correlational analysis showed the largest difference between males and females was between Social Support and the cohesion dimension 
of Group Integration-task. This finding suggests that creating a positive, accepting environment for both individuals and the team is more important to enhance perceptions of the team's task and goal unity for female peer leaders.

The finding that Social Support had more of an influence on team cohesion for female athletes agrees with previous research that suggests female athletes focus more on social relationships than males (Holmes et al., 2010). This is important to keep in mind as it is understood that the cohesion-performance relationship has a stronger effect for female teams (Carron et al., 2002). Therefore, female peer leaders that provide adequate social support to teammates may help improve team performance as well. Previous research has also suggested that athletes serving as social leaders may not be as needed as task leaders since team building can be prioritized off the playing field (Loughead et al., 2006). This does not seem to hold true for female athlete leaders based on the findings of the current study. In fact, the findings of this study suggest that female athlete leadership should emphasize providing social acceptance and support to team members in order to foster a strong task and social cohesion on the team.

It appears that having the peer leaders serving as social leaders may not be as important for male teams. This is due to the finding that Social Support was not a significant predictor of either task or social cohesion for males. It is possible that male athletes simply prefer more Social Support from coaches rather than peer leaders at the collegiate level. This would be in agreement with previous research that indicted male student-athletes prefer more Autocratic and Social Support behavior from coaches (Beam et al., 2004). It is also possible that at an older, more competitive level of sport, the male ego interferes with the desire to look to teammates for social support. However, this question still remains unclear as other researchers found that Social Support is not preferred from coaches by either male or female athletes. In other words, 
little differences exist in regards to preferred leadership across gender (Sherman \& Fuller, 2000). However, this may differ when it comes to preferred behaviors from athlete leaders.

The findings of this study help supplement the diminutive amount of current research on peer leaders and their influence on task and social cohesion. In general, it appears that male and female collegiate soccer players perceive higher social cohesion than task cohesion on their teams. It also appears that both male and female athlete perceive that their peer leaders teaching and training others to improve sport skills has a significant influence on task and social cohesion. However, it may be more important for female peer leaders to provide social support to teammates in order to foster task and social cohesion. Socially supportive behavior from male athlete leaders does not seem to have the same impact on the overall team cohesion. Within the context of previous research, which has shown a significant moderate to large cohesionperformance relationship, it appears that increasing social cohesion with female collegiate soccer players can be very influential in increasing performance (Carron et al., 2002).

\section{Limitations}

A number of limitations were identified for this study. First, many more female participants were successfully recruited. It is possible that the initial introductory email sent out to recruit participants may have been biased towards receiving more responses from female head coaches. This is because the researcher identified in the email having worked with the university's head women's soccer coach. It is possible this attracted the attention of more women's team coaches while also turning away more men's head coaches. Second, another limitation is inadequate external validity resulting from the use of a sample of soccer players that may not be generalizable to other collegiate athletes. It could be that perceptions of this particular group of athletes are different from athletes in other team sports such as football or 
baseball. Third, the Leadership Scale for Sports (LSS; Chelladurai \& Saleh, 1980) that was modified for this study was originally developed to assess perceptions of coach leadership. It has been suggested previously that the LSS may not adequately assess all potential coaching behaviors (Chelladurai, 1998). Therefore, it is also possible that the modified version in this study does not assess all potential peer leader behaviors. Finally, the results of the study may have been affected if individual participants were unable to perceive another peer leader on their team. It was assumed that each athlete on the team (who may or may not be an actual leader) was able to identify another athlete on his or her team who was functioning as a peer leader. If participants filled out the peer leadership questionnaire about their own qualities as a leader, a social desirability effect might have influenced these participants to report higher positive behaviors such as Social Support, Positive Feedback, and Democratic behavior.

\section{Practical Implications and Future Research}

This study has a number of practical implications for athletes, coaches, and sport psychology professionals. Previously, it was known that athlete leaders on teams attempt to increase team cohesion by using more participatory (or democratic) behavior (Dupuis et al., 2006), but it was not understood before this study if male and female peer leaders differed in this behavior and why. One important finding of this study is that peer leaders that exhibit Training and Instruction behaviors have a significant influence on task and social cohesion for both male and females. Clearly, it is not just the coach that can help instruct the players on the team in ways that might improve performance. Male and female athlete leaders, whether formal or informal leaders, should look for opportunities to help instruct their teammates to improve their sport skills. Coaches should also look to help educate their athlete leaders in how to instruct their teammates in a positive, helpful way in order to build a stronger task and social cohesion. 
Sport psychology professionals working with athlete leaders should look to educate athlete leaders during consultation and at leadership workshops and conferences on how to instruct their teammates in ways to improve their performance.

It is also evident from the results of this study that Social Support is much more positively related to social and task cohesion in female teams. Previous research found that male collegiate athletes prefer Social Support and Autocratic Behavior from their coaches, while female athletes prefer Training and Instruction (Beam et al., 2004). This study suggests that when it comes to their peers, Social Support is not as important of an influence on task or social cohesion for male athletes. Therefore, it is important for female athlete leaders to make it a priority to provide an atmosphere of consistent social acceptance and support in order to foster strong team cohesion. It may be more beneficial for head coaches of female teams to focus more on task objectives since their athlete leaders can be more effective as social leaders on the team. Sport psychology professionals working with female teams should emphasize to the team's leaders how important it is to provide social support to other teammates. This can have a very positive impact on both task and social cohesion.

There is still a significant need for research on the role of gender in peer leadership and cohesion. It is an area of importance considering it has been known for some time that many coaches consider their athlete leaders to be crucial to athletic success on the playing field (Gould et al., 1987). More recently, researcher found that effective peer leadership was associated with the players who reported higher task and social cohesion (Price \& Weiss, 2011). The fact that a moderate to large cohesion-performance relationship exists only furthers the need to build cohesive teams through peer leadership training, which could be conducted through workshops, conferences, and other educational avenues. 
Future research should focus on exploring in more depth through qualitative design how exactly peer leaders influence a team's social and task cohesion, and if this differs between males and females. Similar to the study on ice hockey captains by Dupuis et al. (2006), semi structured interviews of both male and female formal and informal leaders might produce more detailed findings of what strategies and behaviors are most effective at fostering strong team cohesion. Additionally, using focus groups with identified athlete leaders may help increase understanding of what behaviors are used most frequently by peer leaders (that may or may not be adequately represented by the modified LSS). For example, modeling appropriate behavior or providing inspiration to teammates are not leadership behaviors assessed by the LSS. It is also important to examine and compare the peer leadership-cohesion in other sports and levels of competition. For example, it is unclear if social Support is as influential on perceptions of cohesion for female basketball teams. Similarly, it is unknown whether football athlete leaders provide social support to their teammates and if so how this affects the social and/or task cohesion on the team. At the youth level of sport, it is also unclear how formal and/or informal leaders exhibit leadership behaviors and what the influence of these behaviors is on team cohesion. These are just some examples of the many avenues of future research that can be conducted on how gender might have an influence on the peer leadership-cohesion relationship. 


\section{References}

Beam, J.W., Serwatka, T.S., \& Wilson, W.J. (2004). Preferred leadership of NCAA Division I and II intercollegiate student-athletes. Journal of Sport Behavior, 27(1), 3-17.

Brawley, L.R., Carron, A. V., \& Widmeyer, W.N. (1987). Assessing the cohesion of teams: Validity of the Group Environment Questionnaire. Journal of Sport Psychology, 9, 275294.

Brawley, L.R., Carron, A.V., \& Widmeyer, W.N. (2002). The Group environment questionnaire test manual. Morgantown, WV: FIT.

Carron, A.V., \& Hausenblas, H.A. (1998). Group dynamics in sport (2 ${ }^{\text {nd }}$ ed.). Morgantown, WV: FIT.

Carron, A.V., Brawley, L.R., \& Widmeyer, W.N. (1985). The development of an instrument to assess cohesion in sport teams: The Group Environment Questionnaire. Journal of Sport Psychology, 7, 244-267.

Carron, A.V., Brawley, L.R., \& Widmeyer,W.N. (1997). The measurement of cohesiveness in sport groups. In J.L. Duda (Ed.), Advancements in sport and exercise psychology measurements (pp. 213-226). Morgantown, WV: FIT.

Carron, A.V., Colman, M.M., Wheeler, J., \& Stevens, D. (2002). Cohesion and performance in sport: A Meta analysis. Journal of Sport \& Exercise Psychology, 24, 168-188.

Chelladurai, P. \& Carron, A.V. (1983). Athletic maturity and preferred leadership. Journal of Sport Psychology, 5, 371-380.

Chelladurai, P., \& Saleh, S.D. (1978). Preferred leadership in sports. Canadian Journal of Applied Sport Sciences, 3, 85-92. 
Chelladurai, P., \& Saleh, S.D. (1980). Dimensions of leader behavior in sports: Development of a leadership scale. Journal of Sport Psychology, 2, 34-45.

Dupuis, M., Bloom, G.A., \& Loughead, T.M. (2006). Team captains’ perceptions of athlete leadership. Journal of Sport Behavior, 29(1), 60-78.

Gardner, D.E., Shields, D.L.L., Bredemeier, B.J.L., \& Bostrom, A. (1996). The relationship between perceived coaching behaviors and team cohesion among baseball and softball players. The Sport Psychologist, 10, 367-381.

Gould, D., Hodge, K., Peterson, K., \& Petlichkoff, L. (1987). Psychological foundations of coaching: Similarities and differences among intercollegiate wrestling coaches. The Sport Psychologist, 1987, 1, 293-308

Holmes, R.M., McNeil, M., \& Adorna, P. (2010). Student athletes’ perceptions of formal and informal team leaders. Journal of Sport Behavior, 33(4), 442-465.

Horn, T.S., Glenn, S.D., \& Campbell, W. (2010). Perceived peer leadership behaviors: Links with adolescent female athletes' anxiety and goal orientation. Sport Science Review, 19(3-4), 239-263.

Jambor, E.A., \& Zhang, J.J. (1997). Investigating leadership, gender, and coaching level using the Revised Leadership for Sport Scale. Journal of Sport Behavior, 20(3), 313-321.

Jowett, S., \& Chaundy, V. (2004). An investigation into the impact of coach leadership and coach-athlete relationship on group cohesion. Group Dynamics: Theory, Research, and Practice, 8(4), 302-311.

Loughead, T.M., \& Hardy, J. (2005). An examination of coach and peer leader behaviors in sport. Psychology of Sport and Exercise, 6(3), 303-312. 
Loughead, T.M., Hardy, J., \& Eys, M.A. (2006). The nature of athlete leadership. Journal of Sport Behavior, 29(2), 142-158.

Murray, N.P. (2006). The differential effect of team cohesion and leadership behavior in high school sports. Individual Differences Research, 4(4), 216-225.

Neubert, M.J. (1999). Too much of a good thing or the more the merrier? Exploring the dispersion and gender composition of informal leadership in manufacturing teams. Small Group Research, 30(5), 635-646.

Nezhad, R.R., \& Keshtan, M.H. (2010). The coach's leadership styles team cohesion and team success in Iran football clubs professional league. International Journal of Fitness, 6(1), $53-61$.

Northouse, P. G. (2001). Leadership: Theory and practice \{2nd ed.). Thousand Oaks, CA: Sage.

Nunnally, J.C., \& Bernstein, I.H. (1994). Psychometric theory (3 ${ }^{\text {rd }}$ ed.). New York, NY: McGraw Hill.

Pease, D.G., \& Kozub, S. (1994). Perceived coaching behaviors and team cohesion in high school basketball teams. Journal of Sport \& Exercise Psychology: NASPSPA Abstracts, $16, \mathrm{~S} 93$.

Price, M.S., \& Weiss, M.R. (2011). Peer leadership in sport: Relationships among personal characteristics, leader behaviors, and team outcomes. Journal of Applied Sport Psychology, 23, 49-64.

Sherman, C.A., Fuller, R., \& Speed, H.D. (2000). Gender comparisons of preferred coaching behaviors in Australian sports. Journal of Sport Behavior, 23(4), 389-406. 
Shields, D.L.L., Gardner, D.E., Bredemeier, B.J.L., \& Bostrom, A. (1997). The relationship between leadership behaviors and group cohesion in team sports. The Journal of Psychology, 131(2), 196-210.

Vincer, D.J.E., \& Loughead, T.M. (2010). The relationship among athlete leadership behaviors and cohesion in team sports. The Sport Psychologist, 24, 448-467.

Westre, K.R., \& Weiss, M.R. (1991). The relationship between perceived coaching behaviors and group cohesion in high school football teams. The Sport Psychologist, 5, 41-54. 


\section{Appendix A: Sample Head Coach Letter}

Hi, my name is Michael Berrebi, and I am a doctoral student in the Sport \& Exercise Psychology program at West Virginia University. I am writing to ask for your voluntary assistance in my master's thesis study. In this study, I plan to investigate the influence of gender on the peer leader-cohesion relationship. In other words, I hope to explore whether there are differences between male and female athlete leaders in the ways that their leadership behaviors influence the cohesion (or unity) of the team.

As a soccer player myself since the age of five, I have always had a passion for the beautiful game. I played soccer competitively until entering college at both the high school level and on travel teams. I am currently fulfilling applied sport psychology internship hours while working with the WVU women's soccer team under Coach Nikki Izzo-Brown. This experience has sparked my intrigue in the leadership-cohesion relationship at the collegiate soccer level.

If you would be willing to participate in my study, I am hoping you will take the time to pass along my survey link at www.surveymonkey.com to the student-athletes on your team. If they are also willing to participate, the athletes can then proceed to fill out basic demographic information and two questionnaires regarding cohesion and leadership.

I want to emphasize that although the process of data collection will not be completely anonymous (I will be asking for school of enrollment, age, and year on team), all information received will be kept confidential, and in no way will any of the collected information be identifiable. Therefore, any presented or published data from this study will not include names, year on team, school of enrollment, or any other identifiable information. I also want to stress that there are no known risks or harm associated with participation in the study.

Please consider this opportunity to assist in my study and help advance the cohesion and leadership knowledge in the sport of soccer and field of Sport \& Exercise Psychology. For your help in the project, I will be sending all participating coaches the complete findings of the study as well as some informational resources regarding team cohesion and effective leadership.

Thank you for your consideration, and if you agree to participate please let me know by email that you have passed along the survey link.

Sincerely,

Michael Berrebi

$============$

Michael E. Berrebi

Graduate Student

Sport \& Exercise Psychology

West Virginia University

Phone: (304)-276-9580

Email: mberrebi@mix.wvu.edu
Dr. Edward Etzel

Principal Investigator

Sport \& Exercise Psychology

West Virginia University

Phone: (304)-293-7062

Email: Edward.etzel@mail.wvu.edu 


\section{Appendix B: Sample Participant Cover Letter}

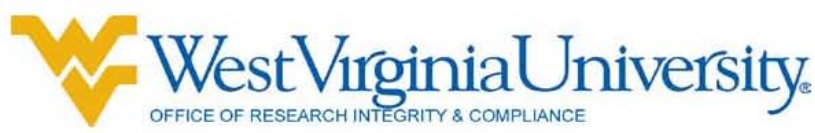

Dear Participant,

This letter is a request for you to take part in a research project to assess how gender influences the peer leadership-cohesion relationship. This project is being conducted by Michael Berrebi, BS in the Department of Sport Sciences at WVU with supervision of Dr. Edward Etzel and Dr. Vanessa Shannon, professors in the College of Physical Activity and Sport Sciences for a Master's Degree in Sport \& Exercise Psychology. Your participation in this project is greatly appreciated and will take approximately 20-25 minutes to fill out the attached questionnaires.

Your involvement in this project will be kept as confidential as legally possible. All data will be reported in the aggregate. You must be 18 years of age or older to participate. I will not ask any information that should lead back to your identity as a participant. Your participation is completely voluntary. You may skip any question that you do not wish to answer and you may discontinue at any time. Your class standing will not be affected if you decide either not to participate or to withdraw. West Virginia University's Institutional Review Board acknowledgement of this project is on file.

I hope that you will participate in this research project, as it could be beneficial in understanding the influence of gender on the peer leadership-cohesion relationship. Thank you very much for your time. Should you have any questions about this letter or the research project, please feel free to contact Michael Berrebi at (304)-276-9580 or by e-mail at mberrebi@mix.wvu.edu.

Thank you for your time and help with this project.

Sincerely,

Michael E. Berrebi

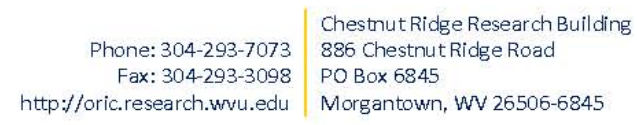




\section{Appendix C: Sample Demographic Questionnaire}

Demographic Information

University/College:

Age:

Gender: $\quad$ Male () Female ()

Year in School: Freshman （） Sophomore （） Junior （） Senior （） Other ()

Race or Ethnicity: Black/African American () White/Caucasian ()

American Indian/Alaskan Native () Hispanic or Latino () Asian or Asian American ()

Other:

Playing Status: $\quad$ Starter () Non-starter ()

Contractual Obligation: Full Scholarship () Partial Scholarship () No Scholarship ()

Gender of Coach: $\quad$ Male ()$\quad$ Female ()

Currently Injured: Yes（） No ()

Last season's Win-Loss Record: 


\section{Appendix D: Group Environment Questionnaire}

\section{GEQ}

The GEQ is a general, rather than situation specific, measure of cohesiveness in sport teams.

\section{Administration}

Should be completed independently, away from distraction, and not immediately before or after a game.

$\underline{\text { Scoring }}$

\begin{tabular}{|c|c|c|c|}
\hline \multicolumn{2}{|c|}{$\begin{array}{l}\text { Individual Attractions to the Group- } \\
\text { Social (ATGS) }\end{array}$} & \multicolumn{2}{|c|}{$\begin{array}{l}\text { Individual Attractions to the Group-Task } \\
\text { (ATGT) }\end{array}$} \\
\hline Item\# & Score & Item\# & Score \\
\hline $1 *$ & & $2 *$ & \\
\hline 3* & & $4 *$ & \\
\hline 5 & & 6* & \\
\hline $7 *$ & & $8 \%$ & \\
\hline \multicolumn{4}{|l|}{9} \\
\hline Sum & & Sum & \\
\hline Mean & & Mean & \\
\hline \multicolumn{2}{|c|}{ Group Integration-Social (GIS) } & \multicolumn{2}{|c|}{ Group Integration-Task (GIT) } \\
\hline Item\# & Score & Item\# & Score \\
\hline $11 *$ & & 10 & \\
\hline $13^{*}$ & & 12 & \\
\hline 15 & & $14^{*}$ & \\
\hline \multirow[t]{2}{*}{$17 *$} & & 16 & \\
\hline & & $18^{*}$ & \\
\hline Sum & & Sum & \\
\hline Mean & & Mean & \\
\hline
\end{tabular}

(*) Items are reverse scored.

Each factor is summed and then an average taken for individuals, and then the team. 


\section{Group Environment Questionnaire (GEQ)}

Name:

Team:

Date:

This questionnaire is designed to assess your perceptions of your team. There are no wrong or right answers, so please give your immediate reaction. Some of the questions may seem repetitive, but please answer ALL questions. Your personal responses will be kept in strictest confidence.

The following statements are designed to assess your feelings about YOUR PERSONAL INVOLVEMENT with this team. Please CIRCLE a number from 1 to 9 to indicate your level of agreement with each of these statements.

1. I do not enjoy being a part of the social activities of this team.

$\begin{array}{llllllllc}1 & 2 & 3 & 4 & 5 & 6 & 7 & 8 & 9 \\ \begin{array}{c}\text { Strongly } \\ \text { Disagree }\end{array} & & & & & & & & \begin{array}{c}\text { Strongly } \\ \text { Agree }\end{array} \\ \end{array}$

2. I'm not happy with the amount of playing time I get.

$\begin{array}{lllllllll}1 & 2 & 3 & 4 & 5 & 6 & 7 & 8 & 9 \\ \begin{array}{c}\text { Strongly } \\ \text { Disagree }\end{array} & & & & & & & & \\ \begin{array}{c}\text { Strongly } \\ \text { Agree }\end{array}\end{array}$

3. I am not going to miss the members of this team when the season ends.

$\begin{array}{llllllllc}1 & 2 & 3 & 4 & 5 & 6 & 7 & 8 & 9 \\ \begin{array}{c}\text { Strongly } \\ \text { Disagree }\end{array} & & & & & & & & \\ \begin{array}{c}\text { Strongly } \\ \text { Agree }\end{array}\end{array}$

4. I'm unhappy with my team's level of desire to win.

$\begin{array}{llllllllc}1 & 2 & 3 & 4 & 5 & 6 & 7 & 8 & \begin{array}{c}9 \\ \text { Strongly } \\ \text { Agree }\end{array} \\ \text { Disagree } & & & & & & & & \end{array}$

5. Some of my best friends are on this team.

$\begin{array}{llllllllc}1 & 2 & 3 & 4 & 5 & 6 & 7 & 8 & 9 \\ \begin{array}{c}\text { Strongly } \\ \text { Disagree }\end{array} & & & & & & & & \begin{array}{c}\text { Strongly } \\ \text { Agree }\end{array}\end{array}$


6. This team does not give me enough opportunities to improve my personal performance.

$\begin{array}{llllllllc}1 & 2 & 3 & 4 & 5 & 6 & 7 & 8 & 9 \\ \begin{array}{c}\text { Strongly } \\ \text { Disagree }\end{array} & & & & & & & & \begin{array}{c}\text { Strongly } \\ \text { Agree }\end{array}\end{array}$

7. I enjoy other parties rather than team parties.

$\begin{array}{cccccccccc}1 & 2 & 3 & 4 & 5 & 6 & 7 & 8 & 9 \\ \begin{array}{c}\text { Strongly } \\ \text { Disagree }\end{array} & & & & & & & & \begin{array}{c}\text { Strongly } \\ \text { Agree }\end{array}\end{array}$

8. I do not like the style of play on this team.

$\begin{array}{ccccccccc}1 & 2 & 3 & 4 & 5 & 6 & 7 & 8 & \begin{array}{c}9 \\ \text { Strongly } \\ \text { Agree } \\ \text { Disagree }\end{array}\end{array}$

9. For me, this team is one of the most important social groups to which I belong.

$\begin{array}{llllllllc}1 & 2 & 3 & 4 & 5 & 6 & 7 & 8 & \begin{array}{c}9 \\ \text { Strongly } \\ \text { Agree }\end{array} \\ \begin{array}{c}\text { Strongly } \\ \text { Disagree }\end{array} & & & & & & & & \end{array}$

The following statements are designed to assess your perceptions of YOUR TEAM AS A WHOLE. Please CIRCLE a number from 1 to 9 to indicate your level of agreement with each of these statements. 
10. Our team is united in trying to reach its goals for performance.

$\begin{array}{llllllllc}1 & 2 & 3 & 4 & 5 & 6 & 7 & 8 & 9 \\ \begin{array}{l}\text { Strongly } \\ \text { Disagree }\end{array} & & & & & & & & \begin{array}{c}\text { Strongly } \\ \text { Agree }\end{array}\end{array}$

11. Members of our team would rather go out on their own than get together as a team.

$\begin{array}{llllllllc}1 & 2 & 3 & 4 & 5 & 6 & 7 & 8 & 9 \\ \begin{array}{l}\text { Strongly } \\ \text { Disagree }\end{array} & & & & & & & & \begin{array}{c}\text { Strongly } \\ \text { Agree }\end{array}\end{array}$

12. We all take responsibility for any loss or poor performance by our team.

$\begin{array}{llllllllc}1 & 2 & 3 & 4 & 5 & 6 & 7 & 8 & 9 \\ \begin{array}{l}\text { Strongly } \\ \text { Disagree }\end{array} & & & & & & & & \begin{array}{c}\text { Strongly } \\ \text { Agree }\end{array}\end{array}$

13. Our team members rarely party together.

$\begin{array}{llllllllc}1 & 2 & 3 & 4 & 5 & 6 & 7 & 8 & 9 \\ \begin{array}{c}\text { Strongly } \\ \text { Disagree }\end{array} & & & & & & & & \begin{array}{c}\text { Strongly } \\ \text { Agree }\end{array}\end{array}$

14. Our team members have conflicting aspirations for the team's performance.

$\begin{array}{llllllllc}1 & 2 & 3 & 4 & 5 & 6 & 7 & 8 & 9 \\ \begin{array}{l}\text { Strongly } \\ \text { Disagree }\end{array} & & & & & & & & \begin{array}{c}\text { Strongly } \\ \text { Agree }\end{array}\end{array}$

15. Our team would like to spend time together in the off season.

$\begin{array}{llllllllc}1 & 2 & 3 & 4 & 5 & 6 & 7 & 8 & 9 \\ \begin{array}{l}\text { Strongly } \\ \text { Disagree }\end{array} & & & & & & & & \begin{array}{c}\text { Strongly } \\ \text { Agree }\end{array}\end{array}$

16. If members of our team have problems in practice, everyone wants to help them so we can get back together again.

$\begin{array}{llllllllc}1 & 2 & 3 & 4 & 5 & 6 & 7 & 8 & 9 \\ \begin{array}{l}\text { Strongly } \\ \text { Disagree }\end{array} & & & & & & & & \begin{array}{c}\text { Strongly } \\ \text { Agree }\end{array}\end{array}$


17. Members of our team do not stick together outside of practice and games.

$\begin{array}{llllllllc}1 & 2 & 3 & 4 & 5 & 6 & 7 & 8 & 9 \\ \begin{array}{l}\text { Strongly } \\ \text { Disagree }\end{array} & & & & & & & \begin{array}{c}\text { Strongly } \\ \text { Agree }\end{array}\end{array}$

18. Our team members do not communicate freely about each athlete's responsibilities during competition or practice.

$\begin{array}{llllllllc}1 & 2 & 3 & 4 & 5 & 6 & 7 & 8 & 9 \\ \begin{array}{l}\text { Strongly } \\ \text { Disagree }\end{array} & & & & & & & & \begin{array}{c}\text { Strongly } \\ \text { Agree }\end{array}\end{array}$




\section{Appendix E: Modified Leadership Scale for Sports}

\section{Leadership Scale for Sports (LSS)}

\section{Dimensions}

Training and instruction (item \#1 to \#13)

Democratic behavior (item \#14 to \# 22)

Autocratic behavior (item \#23 to \#27)

Social support (item \#28 to \#35)

Positive feedback (item \#36 to \#40)

Note: Add the item score to obtain a score for that particular dimension. Divide by the number of items per dimension to get a score out of 5 .

\section{Athlete Leaders in Sport}

Age: $\quad$ yrs. $\quad$ Gender: Female / Male

What level of competition do you play at? (please select one)

Recreational Club Provincial Varsity National

What sport are you participating in? (i.e., hockey, soccer, etc.):

How many years have you been involved in your sport? yrs.

What position do you play on your team? (i.e., goalie, guard, etc.):

How long have you been involved with your current team? 


\section{INSTRUCTIONS}

Athlete leaders are team members who influence other team members. That is athlete leaders can be captains and/or other teammates. Athlete leaders are not coaches. The following questions are designed to assess your opinions about the ATHLETE LEADERS on your team. There are no right or wrong answers. Please take your time to complete the questionnaire and remember to answer the questions honestly. Thank you!

1. How many teammates are on your team?

2. How many athlete leaders are on your team?

3. Who are the athlete leaders on your team?

Please circle THE MOST appropriate option
a) Captain(s)
b) Teammates (not captains)
c) Both captains and teammates

\section{SECTION A}

Using the following scale, please circle a number from 1 to 5 to indicate your level of agreement with each of the statements regarding ATHLETE LEADERS on your team.

\begin{tabular}{|c|c|c|c|c|}
\hline 1 & $\mathbf{2}$ & $\mathbf{3}$ & $\mathbf{4}$ & $\mathbf{5}$ \\
Never & Seldom & Occasionally & Often & Always \\
& $25 \%$ of & $50 \%$ of & $75 \%$ of & \\
the time & the time & the time & \\
\hline
\end{tabular}

The athlete leader(s) on my team...

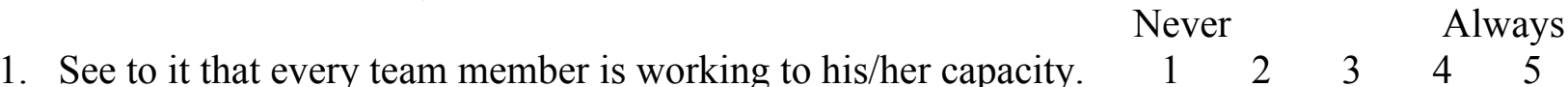

2. Explain to team members the techniques and tactics of the sport. $\quad \begin{array}{llllll}1 & 2 & 3 & 4 & 5\end{array}$

3. Pay attention to correcting team members' mistakes. $\quad \begin{array}{llllll} & 1 & 2 & 3 & 4 & 5\end{array}$

4. Make sure that team members role on the team are understood. $\quad \begin{array}{llllll}1 & 2 & 3 & 4 & 5\end{array}$

5. Instruct team members individually in the skills of the sport. $\quad \begin{array}{llllll}1 & 2 & 3 & 4 & 5\end{array}$

6. Figure ahead on what should be done. $\quad \begin{array}{llllll} & 1 & 2 & 3 & 4 & 5\end{array}$

7. Explain to team members what they should and what they should $\quad \begin{array}{llllll}1 & 2 & 3 & 4 & 5\end{array}$ 
not do.

8. Expect team members to carry out their assignment to the last $\quad \begin{array}{llllll}1 & 2 & 3 & 4 & 5\end{array}$ detail.

9. Point out team members' strengths and weaknesses.

10. Give specific instructions to team members as to what they should do in every situation.

11. See to it that the efforts are coordinated.

12. Explain how team members contributions fits into the total picture.

13. Specify in detail what is expected of team members.

14. Ask for the opinion of team members on strategies for specific competitions.

15. Get team members approval on important matters before going $\begin{array}{llllll}1 & 2 & 3 & 4 & 5\end{array}$ ahead.

16. Let fellow team members share in decision making.

$\begin{array}{lllll}1 & 2 & 3 & 4 & 5\end{array}$

\begin{tabular}{|c|c|c|c|c|}
\hline 1 & $\mathbf{2}$ & $\mathbf{3}$ & $\mathbf{4}$ & $\mathbf{5}$ \\
Never & $\begin{array}{c}\text { Seldom } \\
25 \% \text { of } \\
\text { the time }\end{array}$ & $\begin{array}{c}\text { Occasionally } \\
50 \% \text { of } \\
\text { the time }\end{array}$ & $\begin{array}{c}75 \% \text { of } \\
\text { the time }\end{array}$ & \\
\hline
\end{tabular}

The athlete leader(s) on my team...

17. Encourage team members to make suggestions for ways of

\begin{tabular}{ccccc} 
Never & & \multicolumn{3}{c}{ Always } \\
1 & 2 & 3 & 4 & 5
\end{tabular}
conducting practices.

18. Let team members share in discussion about goals for the team as $\begin{array}{llllll}1 & 2 & 3 & 4 & 5\end{array}$ a whole (e.g., the number of wins over the following month).

19. Let team members try their own way even if they make mistakes. $\begin{array}{llllll}1 & 2 & 3 & 4 & 5\end{array}$

20. Ask for the opinion of team members on important team matters. $\begin{array}{llllll}1 & 2 & 3 & 4 & 5\end{array}$

21. Let team members work at their own speed. $\quad \begin{array}{lllll}3 & 2 & 3 & 4\end{array}$

22. Let team members decide on the plays to be used in a game. $\quad \begin{array}{llllll}1 & 2 & 3 & 4 & 5\end{array}$

23. Work relatively independent of other team members. $\quad \begin{array}{llllll}1 & 2 & 3 & 4 & 5\end{array}$

24. Not explain his/her/their action(s). $\quad \begin{array}{lllll} & 2 & 3 & 4 & 5\end{array}$

25. Refuse to compromise a point. $\quad \begin{array}{lllll} & 2 & 3 & 4\end{array}$

26. Keep to himself/herself/themselves. $\quad \begin{array}{lllll} & 2 & 3 & 4 & 5\end{array}$ 
27. Speak in a manner not to be questioned.

28. Help team members with their personal problems.

$\begin{array}{lllll}1 & 2 & 3 & 4 & 5 \\ 1 & 2 & 3 & 4 & 5 \\ 1 & 2 & 3 & 4 & 5 \\ 1 & 2 & 3 & 4 & 5 \\ 1 & 2 & 3 & 4 & 5 \\ 1 & 2 & 3 & 4 & 5 \\ 1 & 2 & 3 & 4 & 5 \\ 1 & 2 & 3 & 4 & 5 \\ 1 & 2 & 3 & 4 & 5 \\ 1 & 2 & 3 & 4 & 5 \\ & & & & \\ 1 & 2 & 3 & 4 & 5 \\ 1 & 2 & 3 & 4 & 5 \\ & & & & \\ 1 & 2 & 3 & 4 & 5 \\ 1 & 2 & 3 & 4 & 5\end{array}$

Thank you for your participation!!! 


\section{Appendix F: Results Tables}

Table 1

Cohesion and Peer Leadership Subscale Means \& Standard Deviations $(N=381)$

\begin{tabular}{ccccccc}
\hline & \multicolumn{2}{c}{ Overall } & \multicolumn{3}{c}{ Male } & \multicolumn{2}{c}{ Female } \\
\hline Dimension & M & SD & M & SD & M & SD \\
\hline ATG_T & 6.82 & 1.59 & 6.44 & 1.65 & 7.01 & 1.53 \\
ATG_S & 7.49 & 1.45 & 7.38 & 1.46 & 7.54 & 1.44 \\
GI_T & 6.66 & 1.57 & 6.29 & 1.61 & 6.86 & 1.53 \\
GI_S & 7.07 & 1.60 & 6.81 & 1.51 & 7.20 & 1.63 \\
TI & 3.57 & .78 & 3.52 & .77 & 3.60 & .79 \\
DEMO & 3.60 & .87 & 3.62 & .83 & 3.59 & .90 \\
AUTO & 2.40 & .81 & 2.45 & .82 & 2.37 & .80 \\
SS & 3.89 & .85 & 3.87 & .74 & 3.91 & .90 \\
PF & 4.11 & .85 & 4.17 & .73 & 4.09 & .91 \\
\hline
\end{tabular}

Note: ATG-T $=$ Individual Attractions to the Group-Task, ATG-S = Individual Attractions to the GroupSocial, GI-T = Group-Integration-Task, GI-S = Group-Integration-Social, TI = Training and Instruction, $\mathrm{DEMO}=$ Democratic Behavior, AUTO = Autocratic Behavior, SS $=$ Social Support, $\mathrm{PF}=$ Positive Feedback 
Table 2

Cohesion and Peer Leadership Subscale Correlations $(N=381)$

\begin{tabular}{rcccccccc}
\hline \multicolumn{2}{c}{ Dimension } & \multicolumn{2}{c}{ ATG_S } & \multicolumn{2}{c}{ ATG_T } & \multicolumn{2}{c}{ GI_S } & \multicolumn{2}{c}{ GI_T } \\
\hline & M & F & M & F & M & F & M & F \\
\hline TI & .400 & .365 & .419 & .366 & .324 & .463 & .440 & .565 \\
DEMO & .361 & .344 & .342 & .361 & .247 & .403 & .338 & .571 \\
AUTO & -.371 & -.172 & -.262 & -.195 & -.284 & -.237 & -.411 & -.390 \\
SS & .262 & .459 & .375 & .371 & .310 & .469 & .254 & .602 \\
PF & .255 & .432 & .361 & .319 & .334 & .413 & .258 & .545 \\
\hline
\end{tabular}

Note: ATG-T $=$ Individual Attractions to the Group-Task, ATG-S = Individual Attractions to the GroupSocial, GI-T = Group-Integration-Task, GI-S = Group-Integration-Social, TI = Training and Instruction, $\mathrm{DEMO}=$ Democratic Behavior, AUTO $=$ Autocratic Behavior, $\mathrm{SS}=$ Social Support, $\mathrm{PF}=$ Positive Feedback

$* \mathrm{p}<.01$ for all correlations 
Table 3

Stepwise Regressions using Peer Leadership and Cohesion Dimensions $(N=120)$

\begin{tabular}{|c|c|c|c|c|c|c|}
\hline & Predictor Variable(s) & $\mathrm{B}$ & $\mathrm{SE}(\mathrm{B})$ & Beta & Sig. (p) & $\mathrm{R}^{2}$ \\
\hline \multicolumn{7}{|l|}{ Male } \\
\hline \multirow[t]{3}{*}{ ATG-T } & TI/DEMO & - & - & - & - & .237 \\
\hline & TI & -.647 & .224 & -.294 & .005 & .198 \\
\hline & DEMO & .524 & .215 & .248 & .016 & .039 \\
\hline \multirow[t]{3}{*}{ ATG-S } & DEMO/AUTO & - & - & - & - & .212 \\
\hline & DEMO & -.546 & .164 & -.302 & .001 & .164 \\
\hline & AUTO & -.416 & .156 & -.242 & .009 & .048 \\
\hline \multirow[t]{3}{*}{$G I-T$} & TI/AUTO & - & - & - & - & .285 \\
\hline & $\mathrm{TI}$ & -.775 & .178 & -.358 & .001 & .204 \\
\hline & AUTO & -.592 & .162 & -.300 & .001 & .081 \\
\hline \multirow[t]{3}{*}{$G I-S$} & $\mathrm{TI} / \mathrm{PF}$ & - & - & - & - & .175 \\
\hline & $\mathrm{TI}$ & -.507 & .178 & -.267 & .005 & .134 \\
\hline & $\mathrm{PF}$ & .438 & .182 & .225 & .017 & .041 \\
\hline \multicolumn{7}{|l|}{ Female } \\
\hline \multirow[t]{3}{*}{ ATG-T } & $\mathrm{SS} / \mathrm{TI}$ & - & - & - & - & .145 \\
\hline & SS & -.364 & .151 & -.210 & .017 & .120 \\
\hline & $\mathrm{TI}$ & .386 & .168 & .201 & .022 & .025 \\
\hline ATG-S & SS & .681 & .096 & .429 & .001 & .184 \\
\hline \multirow[t]{5}{*}{$G I-T$} & SS/TI/DEMO/AUTO & - & - & - & - & .418 \\
\hline & SS & -.392 & .150 & -.228 & .010 & .347 \\
\hline & $\mathrm{TI}$ & -.479 & .143 & -.251 & .001 & .044 \\
\hline & DEMO & -.301 & .138 & -.173 & .031 & .017 \\
\hline & AUTO & -.221 & .112 & -.117 & .049 & .001 \\
\hline \multirow[t]{3}{*}{$G I-S$} & $\mathrm{TI} / \mathrm{SS}$ & - & - & - & - & .268 \\
\hline & TI & -.621 & .168 & -.299 & .001 & .234 \\
\hline & SS & .491 & .151 & .262 & .001 & .034 \\
\hline
\end{tabular}

Note: ATG-T = Individual Attractions to the Group-Task, ATG-S = Individual Attractions to the GroupSocial, GI-T $=$ Group-Integration-Task, GI-S $=$ Group-Integration-Social, TI $=$ Training and Instruction, 
$\mathrm{DEMO}=$ Democratic Behavior, AUTO $=$ Autocratic Behavior, $\mathrm{SS}=$ Social Support, $\mathrm{PF}=$ Positive Feedback 


\section{Appendix G: Extended Review of Literature}

\section{Section 1: Cohesion}

\section{Nature of Cohesion}

It should come as no surprise that many of the most successful sport teams seem to contain individuals who not only enjoy bonding together over common goals, but also seem to appreciate the other team members on a personal and social level. This concept of team unity is known as cohesion, which is necessary for any type of group to function (Carron, Brawley, \& Widmeyer, 1997). One of the first formal definitions of cohesion by Festinger, Schachter, and Back (1950) was, "the total field of forces which act on members to remain in the group" (p. 164). This definition initially helped to define the idea of cohesion as a sum of two important factors that help keep individual group members attracted to and remain in a group: 1) attractiveness to the group (e.g., the social, connective aspects of the group); and 2) means control (e.g., the performance and goal-achieving features of the group). Although the initial definition by Festinger et al. helped characterize cohesion as a construct involving social and task aspects, it lacked a more comprehensive view of the structure and unique characteristics of cohesion.

Currently, one of the most widely accepted definitions of cohesion is, "a dynamic process which is reflected in the tendency for a group to stick together and remain united in the pursuit of its instrumental objectives and/or the satisfaction of member affective needs" (Carron, Brawley, \& Widmeyer, 1998, p. 213.) This definition was only slightly changed from the original definition of cohesion put forth by Carron (1982) by also taking into account individual members' affective needs, such as feeling cared about and attached to the group. This broad definition is applicable to sport teams because a "team" is a type of "group", and it is well known 
that cohesion has consequences for both the sport team, as well as individual athletes (e.g., Gill, 1986). Furthermore, this definition also touches on some of the fundamental features of cohesion. For example, one of the aspects of cohesion that has been defined is the characteristic of being multidimensional (Carron \& Hausenblas, 1998), meaning there are many reasons teams stick together and become cohesive, and these ways can differ greatly from team to team and sport to sport. Furthermore, the presence of both task and social cohesion is not always necessary for teams to be successful (i.e., a basketball team may be cohesive around obtaining a performance goal but not be socially united off the court). Another characteristic of cohesion is that it is dynamic, or subject to changes over time. For example, a team may be very socially cohesive at the beginning of a promising season only to lack any real resemblance of social or task cohesion after enduring a difficult season. Cohesion is also described as instrumental in nature. In other words, every team (e.g., athletic, volunteer, or industrial) comes together for a purpose that can be task or social-oriented, or both. Finally, cohesion has affective aspects, meaning it can fulfill the affective needs of individual group members through social and task interactions and communication (Carron \& Hausenblas, 1998).

Since cohesion is characterized by togetherness in both a social and performance-based way, there was an obvious need to differentiate between its social and task-related components. Mikalachki (1969) was one of the first to distinguish between task and social dimensions of cohesion, noting a social and task "focus" in groups (p. 55). Mikalachki also proposed these two components were unique in how they were established and how they affected the group. These foci represent social cohesion- the degree to which team members are attracted to and appreciate the team as a whole, and task cohesion- a reflection of the degree to which a team works together to accomplish specific goals and objectives. 
The need to distinguish specifically between individual and group constructs of cohesion was later addressed by Carron, Widmeyer, and Brawley (1985) with the development of four correlated constructs of cohesion. These constructs resulted from initially defining the first major dimension of cohesion, Group Integration (GI), as the individual group members' views of the group as a whole. This dimension reflects the degree of perceived wholeness or bonding in the group. The second dimension, Individual Attractions to the Group (ATG), represents the individual group members' attractions to the group. This dimension reflects the perceptions of each individual team member such as their fit in the group or overall happiness with group goals and challenges. These two dimensions were then incorporated into both task (GI-T, ATG-T) and social (GI-S, ATG-S) constructs. Collectively, these four constructs of cohesion make up a conceptual model for studying cohesion in the athletic environment.

It is important in the understanding of cohesion to determine what factors influence its overall development and structure. Carron and Hausenblas (1998) addressed this question by defining four comprehensive factors. Those factors are: 1) environmental (i.e., physical proximity of group members and team size); 2) personal (i.e., competitive state anxiety and individual satisfaction); 3) team (i.e., defined roles and communication); and, 4) leadership factors (i.e., coaching style and player-coach compatibility). The relationship between these factors is dynamic and complex. In addition, the four different factors are not independent and subject to influence each other in the development of team cohesion.

\section{Assessing Cohesion}

The task of statistically measuring such a dynamic, multidimensional construct is not easy to fulfill. The Sport Cohesiveness Questionnaire (SCQ; Martens, Landers, \& Loy, 1972, as cited in Gill, 1986) was one of the original instruments used to assess cohesion in sport teams. 
According to Bird and Cripe (1986), the 7-item questionnaire assessed two main categories: 1) socially related ratings of the group (i.e. interpersonal attraction and personal power or influence); and 2) measures of cohesion within the group (value of membership, sense of belonging, closeness, teamwork, and enjoyment). This instrument was important in providing a foundation for comparing multiple studies examining cohesion in sport (Gill, 1986). However, several limitations existed in this early instrument to assess cohesion. These limitations included a lack of task and social measures and other important psychometric properties such as construct and content validity, as well as adequate reliability scores (Carron et al., 1997; Gill, 1986).

Historically, cohesion has been most frequently assessed quantitatively through the use of questionnaires. Currently the most common way to investigate cohesiveness in teams is through the use of the Group Environment Questionnaire (GEQ), which was developed by Carron et al. (1985). The GEQ was originally constructed in response to several underlying issues in the applied assessment of cohesion. For example, cohesion was being assessed by several different methods and therefore studies on cohesion could not be properly compared and contrasted. Important psychometric properties were also missing or inadequate from the existing cohesion measures (e.g., the Sport Cohesiveness Questionnaire). Finally, the current cohesion measures did not appear to properly assess individual members' attraction to the group, a principal component of cohesion.

Based on these perceived shortcomings, the GEQ was created to assess two main constructs, the individual group members' perceptions of the group as a whole (group integration) and individual members' attraction to the group (Carron et al., 1985). These constructs are separated into four interrelated subscales incorporating task and social cohesion components. The four subscales include: 1) Group Integration-Task (GI-T); 2) Group 
Integration-Social (GI-S); 3) Individual Attractions to the Group-Task (ATG-T); and 4) Individual Attractions to the Group-Social (ATG-S). Overall, the 18-item questionnaire was designed to capture individual group members' perceptions of the team as a cohesive unit in regards to their view of the group as a whole, as well as their own feelings of attraction to the group.

The GEQ is arguably still the best and most common way to assess cohesion. A key strength of the GEQ is the ability to assess many different sport teams with various team characteristics. It has also been found to have strong internal consistency and adequate content validity (Brawley et al., 1987; Carron et al., 1985). However, the GEQ is not without its shortcomings. Several limitations have also been put suggested such as a lack of research available to ensure adequate construct validity. Also, the GEQ does not take into account any external perceptions of the group that is being assessed for its cohesiveness (Carron et al., 1985). In addition, it has been shown that using all positive wording in a revised GEQ significantly raised the internal consistency on three of the dimensions of cohesion excluding Individual Attractions to the Group-Task (Eys, Carron, Bray, and Brawley, 2007). This improved the instrument as a sufficient assessment of team cohesion.

Soon after the GEQ was published, Brawley et al. (1987) assessed the concurrent validity, predictive validity, and content validity of the GEQ in three separate studies. In the first study, the researchers found concurrent validity with the GEQ compared to other instruments used to measure cohesion such as the SCQ. In the second study, adequate predictive validity was established for the GEQ by using task cohesion scores to accurately determine athletes' membership to either individual or team sports. In the third study, construct validity was determined by looking at predicted discrepancies among reported self-attributions between high 
and low task-cohesive team sport athletes. Although the three studies on the validity of the GEQ showed it was a reliable and valid instrument to be used when measuring cohesion in sport teams, Brawley et al. cautioned that future researchers should continue to test the validation of the GEQ's social and task scales.

\section{Cohesion in Sport}

Most successful teams have a degree of cohesiveness that allows the team to function well in a positive atmosphere conducive to success (Yukelson, 1997). Therefore, one of the most prominent questions that has been asked about athletic teams is "does cohesion cause greater performance?" After completing a review of the literature on the cohesion-performance relationship, Gill (1977) suggested that an intuitively positive relationship could not be taken as empirically valid because the results of other studies showed a negative or non-existent relationship (e.g., Landers \& Luschen, 1974). This uncertainty was further examined by Mullen and Copper (1994) in a meta-analysis on the relationship between cohesion and performance. The results of the meta-analysis indicated that there was in fact a very significant but small cohesion-performance relationship. Furthermore, the authors noted that this relationship was stronger in groups of smaller size, real groups, and stronger in correlational studies. Finally, the relationship was reported to be due mostly to the task aspect of cohesion. Directionally, the performance to cohesion relationship was found to be stronger than the cohesion to performance relationship.

More recently, Carron, Colman, Wheeler, and Stevens (2002) published a meta-analysis on the cohesion-performance relationship in sport. The researchers noted that the meta-analysis was necessary due to several glaring deficiencies in the 1984 cohesion-performance metaanalysis by Mullen and Copper. One such deficiency was the inability to generalize the results 
to the sport domain. This was proposed because the Mullen and Copper meta-analysis reviewed research that included many different types of groups (e.g., military or business). A number of other issues were highlighted such as the original meta-analysis failing to contain any unpublished and only one-third of the available refereed publications in sport sciences.

Several important results were reported from the 2002 meta-analysis on the cohesionperformance relationship. Carron et al. found an overall significant moderate to large relationship. A reciprocal relationship was also found between both social and task cohesion. In contrast to Mullen and Copper's findings, no significant difference was reported between the cohesion-performance and performance-cohesion relationship. Interestingly, the meta-analysis reported that, in contrast to previous findings, social cohesion was more strongly related to performance than task cohesion (i.e., having a team that is socially cohesive is more important to success than a team that is cohesive around a particular task or goal). Finally, in regards to gender, Carron et al. reported a larger cohesion-performance relationship for female athletes/teams than males that was statistically significant. The researchers also suggested that gender mediated the cohesion-performance relationship, and this result could indicate that female athletes and teams are more susceptible to detrimental effects stemming from cohesion issues.

Researchers have long been conducting research on how group cohesiveness effects team success and satisfaction. Martens \& Peterson (1972) conducted a study using male intramural basketball players and found that if two components of cohesion (level of teamwork and value of team membership) were high, teams were more successful. A stronger sense of belonging, however, did not correlate to more success as a team. The researchers suggested a potentially circular relationship between team cohesion, satisfaction, and success. In other words, more cohesive teams tend to be more satisfied than unsuccessful teams. Satisfaction, the mediating 
variable, then leads to more cohesion within the team. Results of other studies have supported this relationship (e.g., Williams \& Hacker, 1982, using the SCQ), however, it should be noted that there are methodological limitations to these studies since they were conducted before the four constructs of cohesion or the GEQ were formulated.

Other researchers have also demonstrated the importance of cohesion in sport teams. For example, Brawley, Carron, and Widmeyer (1993) conducted a study looking at the cohesion of groups and perceptions of goal-related variables in adult and community college athletes. Results included that the variable of group cohesion was related to team satisfaction with identified group goals. The researchers also found cohesion to be higher among group members that perceived their team to use goal setting in preparation of competition. In addition, the perception that the team was in some way cohesive was strongly related to group satisfaction with practice and competitive goals (Brawley et al., 1993). It was suggested that future researchers investigate whether cohesion is necessary for athletes to perceive team satisfaction with goals.

\section{Section 2: Leadership}

\section{Definition and Theory of Leadership}

Throughout history, many of the most successful, iconic athletes have been characterized as leaders both on and off the field of play. But what exactly does "leadership" mean? There are many ways to identify and describe leadership. Northouse (2001) defined leadership comprehensively by suggesting it is, "a process whereby an individual influences a group of individuals to achieve a common goal" (p. 3). The importance of leadership on sport teams is evident as it is one of the four main factors originally defined by Carron and Hausenblas (1998) that influences the development of cohesion. Additionally, it is well know that successful, 
cohesive teams must have strong leadership that promotes each individual athlete to have a solid understanding of their role on the team (Yukelson, 1997).

The Northouse (2001) definition of leadership emphasizes several characteristics that are important to its composition. First, leadership is a process, suggesting that it is not necessarily a trait but a dynamic, ongoing interaction between leaders and individual followers (Loughead \& Hardy, 2006). The second important component of leadership is that the leader must exert some type of influence on group members. It should be noted, however, that this influence is not necessarily positive for all groups, which can subsequently hinder performance and success. A third feature of leadership is that it is established in groups, and a fourth characteristic is the presence of goals. A central tenet of leadership is the leader effectively working towards the realization of team and individual goals (Loughead \& Hardy, 2006).

Several theories and models of leadership exist in the sport psychology research, but one of the most prominent models in the athletic domain is the Multidimensional Model of Leadership (MML; Chelladurai 1978, as cited in Chelladurai \& Riemer, 1998). Unlike some of the existing theories that contributed to its construction, the MML puts significant and equal emphasis on the relationship between the leader, team members, and outside factors (Chelladurai \& Riemer, 1998). The MML proposes that team performance and individual member satisfaction are dependent on the agreement of three different facets of coaching leadership behavior: 1) actual behaviors, 2) individual members' preferred leader behaviors; and 3) required leader behaviors. Influencing the type of behavior shown by coach leaders are different antecedents that include situational (e.g., team structure or values), leader (e.g., personality or athletic experience), and team member factors (e.g., age or gender). 
A significant amount of research has stemmed from the MML and the idea that team performance and member satisfaction is dependent on actual, preferred, and required leadership behaviors. Most of these studies have used a quantitative measure to assess leadership and have attempted to examine a number of antecedent variables such as team goals, personality, and gender in relation to preferred or perceived coaching behaviors (e.g., Dupuis, Bloom, \& Loughead, 2006). It should be noted, however, that the MML is not without a few limitations. While the MML presents a fairly comprehensive view of what factors influence coaching behavior and how that behavior may influence team performance and individual team member satisfaction, it was not constructed to represent athlete leadership behaviors. Furthermore, the MML was based mainly on adult and elite athlete leadership and therefore may not be applicable in a youth sport setting (Chelladurai \& Riemer, 1998).

\section{Assessing Leadership}

Soon after introducing the Multidimensional Model of Leadership, Chelladurai and Saleh (1980) recognized that a novel instrument was needed to test the constructs of the theory. While other leadership instruments had been used in previous research in organizational settings, it was unclear what dimensions and specific items of these instruments were relevant in the realm of sports. Subsequently, the Leadership Scale for Sports (LSS; Chelladurai \& Saleh, 1980) was created using existing leadership instruments as a foundation. The scale was soon reviewed by the original researchers and revised to consist of 40 total items that assessed the five dimensions of leadership behavior using five total factors: 1) Training and Instruction; 2) Democratic Behavior; 3 Autocratic Behavior; 4) Social Support; and 5) Positive Feedback.

These five unique factors do not encompass every aspect of leadership, but instead focus on the five most meaningful aspects that reflect coaches' leadership behaviors. Training and 
Instruction (13 items) refers to the coach instructing and training athletes to help them reach their performance potential. This factor also refers to the coach using their knowledge and skills to instruct and help improve athletes' skill, as well as to coordinate overall team activities. The second factor, democratic behavior (9 items), refers to the coach allowing team goals and decision making to remain open to the entire team and not be determined only by the coach. Conversely, Autocratic Behavior (5 items) represents the coach taking sole responsibility over team decisions and goals and expecting full observance from athletes of all team decisions. Social Support ( 8 items) reflects the coach seeking involvement and a positive climate in interpersonal relations with the athletes. This factor is independent of a team member's individual performance. Finally, Positive Feedback (5 items) refers to the coach staying positive even in difficult or losing situations and complimenting and showing appreciation for athletes' performance and efforts. Separated into the type of leadership factor, the LSS contains one direct task or instructional factor (Training and Instruction), two decision-making factors (Democratic and Autocratic Behavior), and two motivational factors (Social Support and Positive Feedback), according to Chelladurai and Saleh (1980). The LSS can be distributed in three different versions with respect to coaching leadership behaviors: 1) athlete's preferences for desired coaching behaviors; 2) athlete's perceptions of how the coach behaves; and 3) coach's evaluation of self-described behaviors (Gardner et al., 1996). These versions represent the three different leadership aspects that collectively determine athlete performance and satisfaction in Chelladurai's Multidimensional Model of Leadership.

In the same Chelladurai and Saleh (1980) article that contained descriptions and definitions of the five dimensions of leadership, test-retest reliability and other psychometric properties were established. Internal consistency and test-retest reliability scores were found to 
be adequate using Cronbach's alpha. Furthermore, factorial validity was confirmed when the scale was administered to different samples and the leadership factors remained relatively stable across samples. The authors also established content validity by interpreting and defining the five leadership factors included in the LSS (Chelladurai \& Saleh, 1980).

The LSS was later analyzed and reviewed by Chelladurai and Riemer (1998), and several issues were reported with the leadership scale. First, because the LSS evolved from pre-existing leadership scales from business and industrial sectors, the five leadership factors may not fully incorporate all of the potential coaching behaviors in sport. Furthermore, the LSS does not account for any coaching behaviors that are related to transformational leadership or athlete satisfaction with coaching behavior. Finally, issues were reported in the accuracy of measuring actual behaviors by simply averaging individual team members' perceptions of leadership behaviors. The authors also commented on the issue that team members' perceptions of coaching behavior do not always necessarily reflect the actual coaching behaviors. Finally, coaches can sometimes behave in specific ways with different athletes (Chelladurai \& Riemer, 1998).

Zhang, Jensen, and Mann (1997) focused on addressing some of these shortcomings in revising the LSS. Zhang et al. modified the number and content of a number of items in the LSS after interviewing intercollegiate coaches. The goal was to create a more sport specific scale with better psychometric properties for the actual coach self-evaluation version. Furthermore, the revision study was conducted in the United States and so was not subject to any cultural bias. It was also conducted with larger samples, which helped to improve the generalizability of the instrument. The 60-item Revised Leadership Scale for Sport (RLSS) was ultimately created to include a new factor, "situational consideration behavior", which reflects coaching behaviors that 
recognize situational factors, both controllable (e.g., team and individual) and uncontrollable (e.g., time or environment). This factor also represents coaches using different coaching techniques in different stages of group development and giving each individual athlete specific and appropriate roles on the team (for example, by position or by leadership role). There are no considerable differences in the role of the LSS and RLSS in assessing athletes' perceived and preferred coaching behaviors and coaches' self-reported behavior. The RLSS also contains three versions that could be used individually or together to investigate athlete or coach leadership styles (Zhang et al., 1997).

\section{Leadership Characteristics}

Every sport team, group, or organization operates based on certain goals and aspirations. It is the responsibility of leaders to meet these goals and objectives in order to be considered successful and effective (Carron \& Eys, 2012). Within groups, Carron and Hausenblas (1998) originally identified two major types of roles for leaders- formal and informal. The group directly establishes formal roles, and individuals in formal roles must be responsible for two main tasks: 1) ensuring the demands of the group are satisfied (such as goals, tasks, or objectives); and 2) ensuring needs and aspirations of members are satisfied. In a sport team, head and assistant coaches, as well as captains can serve the team in a formal role. For coach leaders, it is likely (especially as the level of competition rises) that the main task they are responsible for is winning games. When this demand is not met the coach is usually held accountable and replaced or criticized.

Alternatively, informal roles may also arise from the interactions and communication among group members. No coach or team member officially appoints this type of role. Furthermore, the expected behavior of individuals in informal roles within a team is not as well 
established as the behaviors of individuals in formal roles (Carron \& Eys, 2012). Examples of potential informal roles on a team include the enforcer, star player, or team comedian (Carron \& Hausenblas, 1998). As expected by the diversity of informal role types, both positive and negative consequences can arise from the influence of informal leaders such as a mentor role (beneficial) or a cancer role (detrimental to team performance).

Based on these two main types of roles, Carron and Eys (2012) recently identified individuals who emerge from informal roles to become leaders as emergent leaders. Furthermore, formal leaders (i.e., officially appointed by the team/organization) were labeled as prescribed leaders. It is important to note that both types of leaders in a sport team can be either athlete or coach leaders. Carron and Hausenblas (1998) originally suggested that all leaders within a team serve internal functions (for example, tend to the social and task needs of group), as well as external functions (for example, help the team adapt and cope with the external environment, represent team at meetings, in public, or at media conferences). However, research has historically focused on coaching leadership (e.g., Murray, 2006; Shields et al., 1997). More recently, the impact of peer leaders in sport teams has been examined (e.g. Vincer \& Loughead, 2010).

The concept of athlete leadership was recently defined by Loughead et al. (2006) as, “... an athlete occupying a formal or informal role within a team who influence a group of team members to achieve a common goal" (p. 144). Loughead et al. also classified two types of athlete leaders: 1) team leaders (50\% agreement by team members); and 2) peer leaders (leaders who influenced at least two other team members). Based on this definition, it is clear that within an interactive sport team, there can be many different leaders. Team leaders are officially agreed upon and appointed by at least half of the team, while peer leaders informally influence at least 
two other team members through communication and interaction. It should be noted that the term "peer leader" has been most prominently used interchangeably with "athlete leader", and so for all intensive purposes these terms refer to the same type of individual.

Another important concept regarding leadership on sport teams is leadership dispersion. This idea was initially put forth by Neubert (1999) and identified as the percentage of athlete leaders for both team and peer types of leaders. A dispersion statistic could be calculated by taking the number of leaders on a team divided by total team size. Neubert, who proposed leader dispersion could both help and hinder team functioning, initially put forth the idea of communication as a potential mediator of this relationship. Neubert essentially proposed that situations could arise of either "too many cooks in the kitchen" or "the more the merrier". In other words, having smaller leadership dispersion could enhance communication within the team and reduce internal conflicts. On the other hand, more athlete leaders could lead to positive functioning by allowing for much more openness in opinions and information flow throughout the team.

Hardy, Eys, and Loughead (2008) examined whether communication mediated the athlete leadership-cohesion relationship. The researchers suggested (as mentioned previously) Neubert advocated that the quality of communication could mediate the relationship between athlete leadership and cohesion. Hardy et al. found that task leadership dispersion was negatively related to task cohesion and communication, with communication being a significant mediator of the task leadership-task cohesion relationship. The results of the study favor Neubert's idea of "too many cooks in the kitchen". In other words, for task cohesiveness, smaller leader dispersion is favorable, with good communication being a very important variable in the equation. It should 
be noted that the results of this study are only generalizable to collegiate, interactive teams.

Furthermore, gender as a mediating variable was not examined in the study.

\section{Coach Leadership in Sport}

In sport teams, one of the most crucial roles of the coach is to help athletes consistently produce their best performances (Martens, 1987). Research has shown the important influence of coaches on the performance of athletes and teams. For example, Greenleaf, Gould, and Dieffenbach (2001) found in a qualitative study of Olympic athletes that having a trusting and friendly relationship with coaches and having coaches with good preparation were factors related to positive performance. Furthermore, the same athletes also reported some negative performance factors related to coaching. These included power struggles with coaches, coaches' lack of focus on overall team dynamics and technical feedback, and failure of coaches to respond to controversies (Greenleaf et al., 2001).

Other performance factors such as athlete stress have been examined qualitatively in the literature. Fletcher and Hanton (2003) examined the influence of the coach-athlete interaction on athlete stress and found that leadership issues such as coach-athlete tension, coaches that lack adequate communication, and non-supportive coaches were among the highest sources of stress identified by elite athletes. In addition, other sources of stress for athletes involved a lack of communication between athletes and managers and unapproachable team managers. The fact that the coach of a team can be both an instructive, supportive leader and a high source of stress only serves to highlight the influence of the coach on the team as a whole and each individual athlete.

Most of the leadership research in sport and exercise psychology has involved the coach as a leader. For example, Jambor and Zhang (1997) used the RLSS to examine differences in 
perceived coaching leadership behaviors between gender and level of experience. This was achieved by administering the coach self-evaluation version of the RLSS to junior high, high school, and collegiate coaches. Significant differences in the leadership domains of Training and Instruction, Democratic Behavior, and Social Support were found between level of experience but not gender. Coaches perceived no significant interactions between gender and coaching level.

Research has also looked at the athletes' preferred leadership qualities of their coaches. An early study by Chelladurai and Saleh (1978) using questions from existing leadership scales found that Canadian University athletes differed by gender in preferred coaching leadership behavior. Male athletes preferred Autocratic Behavior and Social Support more than female athletes. In a related study, Chelladurai and Carron (1983) looked at the relationship between preferred coaching leadership style and age of basketball players. It was found that the preference for Training and Instruction progressively decreased from midget level to varsity before increasing at the intercollegiate level. Preference for Social Support and Autocratic Behavior progressively increased through all levels of play. The researchers suggested that the results of the study did not support the situational theory of leadership that proposes that leaders need to adapt behaviors to match the maturity of group members.

Other research has shown that among NCAA Division I and II athletes, gender differences were found in preferred coach leadership behaviors. Using the RLSS, male athletes showed significantly more preference for Autocratic Behavior and Social Support, while female athletes preferred Situational Consideration and Training and Instruction behaviors. No significant differences in preferred leadership behaviors were found among competition level (Beam, Serwatka, \& Wilson, 2004). 
In contrast to the findings by Beam et al. (2004), a study conducted by Sherman, Fuller, and Speed (2000) found no significant gender differences in preferred leadership style for athletes in single-gender and dual-gender sport teams in Australia. Across single-gender male (football), single-gender female (netball), and dual-gender (basketball) sports, the only significant gender difference reported was that female athletes had a slightly greater preference than males for Democratic leadership style and Positive Feedback. Overall, both male and female athletes had little preference for Autocratic Behavior from coaches. Results of the study indicate athlete gender may not be as important as previously thought (e.g., Chelladurai, 1980) in determining preferred coaching behaviors. A limitation of this study, however, is that it focused only on Australian athletes, and their differences compared to American collegiate and elite athletes should not be underestimated.

\section{Peer Leadership in Sport}

While the coach as a leader is prominent throughout the literature, more recently athletes as leaders have been examined in the realm of sports leadership. These leaders are an important part of the sport team, and research suggests that coaches consider peer leaders to be an important piece to athletic success on the playing field (Gould, Hodge, Peterson, \& Petlichkoff, 1987). What characteristics set athlete leaders on teams apart from their non-leader teammates? One study on female soccer players showed using the Sport Leadership Behavior Inventory (SLBI) that athlete leaders were rated lower by their peers in competitive anxiety and higher in self-esteem, sport competence, and soccer competence than non-leaders (Glenn \& Horn, 1993). It was found that athletes who played in more centrally located positions were more likely to function as leaders compared to players in non-central positions. Furthermore, athletes who rated themselves higher in masculinity and femininity (i.e. androgynous) also rated themselves as 
high in leadership ability. Not surprising, coaches' leadership ratings were also used in this study but tended to correlate mainly with actual skill competence of the athlete. This finding is in agreement with the results of a 1981 study by Yukelson, Weinberg, Richardson, and Jackson that showed leadership status among collegiate soccer and baseball players was significantly related to the coaches' ratings of actual athletic performance.

Loughead and Hardy (2005) examined perceptions of coach and peer leadership behaviors on sport teams. Results of the research showed several key differences in leadership behavior. First, athletes perceived coach leaders to display more Training and Instruction and Autocratic Behavior than peer leaders. Subsequently, peer leaders on a team were perceived to show higher amounts of Social Support, Positive Feedback, and Democratic Behaviors. The researchers also examined the structure of peer leadership on teams, finding that two-thirds of athletes typically perceived that captains (formal) and other teammates (informal) were acting as leaders. The other one third of athletes reported that only captains were peer leaders on the team. Overall, athletes reported that about one quarter of the individual team members served a leadership role on the team (Loughead \& Hardy, 2005). This study was important because it highlighted the idea that coach and athlete leadership is not equivalent and can serve very different functions on sport teams. The authors of the study also pointed out that a leadership scale specifically for peer leaders should be constructed since the only instrument available to assess peer leadership was a slightly modified version of the LSS, which was originally created to assess only coach leadership behaviors.

In another study on athlete leadership, Loughead, Hardy, and Eys (2006) identified both types of athlete leaders (i.e., peer and team leaders) serving all three functions of social, task, and external leadership in athletes. Furthermore, formal leaders were more likely identified as team 
leaders (50\% agreement by team members) and informal leaders were most likely identified as peer leaders (influenced at least two team members). Not surprising, the majority of athlete leaders were starters and were also found to remain in a leadership role at the end of the season. An important finding in this study was that athlete leaders were most related to task leaders. In other words, it was suggested that athlete leaders also serving as social leaders may not be as necessary as task leaders since more team-building and social cohesion activities can be implemented outside of the playing field.

The relationship between perceptions of athlete leader dispersion and athlete satisfaction over a season was investigated by Eys, Loughead, and Hardy (2007). The researchers found that athletes that perceived the three leadership functions to be represented equally by team leaders were more satisfied with team performance and integration than those who perceived an imbalance in the number of functional leaders. Therefore, it is clear that team satisfaction and feelings of integration are not necessarily dependent on the number of team leaders, but more reliant on the three leadership functions of social, task, and external being equally represented. The findings of this study point to the importance of the quantity (but not necessarily the quality) of peer leaders serving various leadership roles.

Similar to coach leadership, athlete leadership has consequences for non-leaders on sport teams. For example, a study on elite adolescent female soccer players using a modified version of the LSS, the Peer Leadership Scale for Sports (PLSS), found that athletes that perceived their peer leaders to exhibit Democratic leadership style and a high degree of Social Support, Positive Feedback, and Training and Instruction scored higher on mastery and performance goal orientation (Glenn, Horn, \& Campbell, 2010). Alternatively, the researchers also reported that 
these same athletes exhibited higher competitive trait anxiety, an unfavorable characteristic, when their peer leaders demonstrated autocratic rather than democratic leadership behaviors.

Price and Weiss (2011) recently researched athlete leadership in sport using transformational leadership theory. Female soccer players $(\mathrm{N}=191)$ on competitive U.S. Youth Soccer teams assessed peer leaders on leadership behaviors. Peer leaders were characterized by a higher degree of soccer competence, social acceptance, behavioral conduct, and intrinsic motivation. In addition, the results of the study showed that effective peer leadership was associated with the players who reported higher task and social cohesion. Therefore, it can be said that athlete leaders play an important role in team members' perceptions of cohesion. Unfortunately, gender differences were not examined in this study.

Fewer studies have examined peer leadership in sport qualitatively through the use of interviews. In one qualitative study on male ice hockey captains, Dupuis et al. (2006) discovered using semi-structured interviews three main categories that represented the team captains' perceived leadership qualities. The first, interpersonal characteristics and experience, included the captains having early exposure to sport and a high level of competition, being good communicators, staying positive and respectful with coaches and teammates, and having control of emotions. Verbal interactions were also recognized, meaning it was important for captains to have a trusting, open relationship with coaches while at the same time being careful not to ostracize teammates. This category also included being effective at interacting in different ways with different teammates. Finally, task behaviors were perceived as important for captains (i.e. set the right example both on and off the ice and be effective at improving the team climate, norms, and functioning (Dupuis et al., 2006). One drawback of this study is that only male team 
captains from winning teams were analyzed. More research should look at informal captains' leadership behaviors as well as female athlete leadership.

Holmes, McNeil, and Adorna (2010) more recently conducted a qualitative study looking at collegiate athletes' perceptions of both formal and informal peer leaders. Many of the results of this study are important because gender differences were analyzed between male and female athletes. For example, both male and female athletes believed athlete leaders should be vocal and trustworthy, lead by example, be role models, and possess good interpersonal skills. Likeability was not an important factor for male or females. However, it was more important for females for athlete leaders to be vocal, sensitive, and have good interpersonal skills, while males were more concerned with trustworthiness and experience. Women also perceived attitude of team leaders to be more about demeanor than attitude about winning and losing. The researchers suggested that perhaps female athletes focused more on social relationships than males. Comparing coach and athlete perspectives of athlete leaders with respect to leadership was also proposed as an important path for future research.

It seems overall that it is unclear how exactly gender plays a role in regards to peer leadership in sports. While some studies have suggested that females peer leaders tend to be more democratic and give social support, others have not found any gender differences. There is also some uncertainty regarding how the gender of individual team members affects perceived athlete leadership behaviors. In addition, it seems more research needs to be conducted on peer leadership in sport to determine how male athletes lead compared to female athletes and how this leadership behavior affects important team factors such as performance, communication, and cohesion. 


\section{Gender Differences in Leadership}

Do men and women lead differently or is gender just an inconsequential characteristic of a leader? Eagly and Johnson (1990) noted the existence of the stereotypic idea that men tend to lead with a more task-oriented style, while women are expected to lead with the focus on interpersonal relations. In a meta-analysis on leadership style in social and industrial psychology, Eagly and Johnson (1990) found that female leaders usually adopted a democratic and participatory style, while men tended to lead more autocratically. This finding was consistent across all laboratory, organizational, and assessment studies. However, it was also found that in organizational studies, men and women did not differ in their style of leadership (task or social-oriented). Although athletic teams were not used in the analyses, many sport teams operate similarly to organizational groups.

In the MML theory, Chelladurai and Saleh proposed that one of the antecedents that influences coaching leader behavior is team member factors, such as gender. In fact, Chelladurai and Saleh (1978) initially put forth the idea of gender mediating differences in preferred leadership style. Since then research seems ambiguous in whether gender differences exist in preferred coach leadership style (e.g., Beam, Serwatka, \& Wilson, 2004; Sherman, Fuller, and Speed, 2000). Research has shown that cohesion is positively related to performance (Carron, Colman, Wheeler, and Stevens, 2002), so a logical next step in studying leadership is to investigate how different leadership styles influence team cohesion. 


\section{Section 3: The Cohesion-Leadership Relationship}

\section{The Coach Cohesion-Leadership Relationship}

Literature on the relationship between coaching leadership style and cohesion is extensive. Westre and Weiss (1991) looked at the relationship between perceived coaching behavior and cohesion in high school football teams. Results showed that coaches high in Training and Instruction, Social Support, Positive Feedback, and Democratic Behaviors were associated with high levels of cohesion. Perceptions of high success on teams were related to more perceived positive coaching styles and task cohesion. Interestingly, starters perceived higher levels of ATG-T than non-starters but neither differed in overall perceptions of coaching behaviors. This study was important because it was one of the first to use both the LSS and GEQ in studying the leadership-cohesion relationship (Gardner et al., 1996).

Much of the research on the relationship between cohesion and coaching leadership style since the Westre and Weiss study has investigated the relationship using both the LSS and GEQ. For example, Gardner et al. (1996) looked at how perceived coaching behaviors were related to cohesion in baseball and softball players. They found that coaches that were perceived as high in Training and Instruction, Democratic Behavior, Social Support, and Positive Feedback and low in Autocratic Behavior had teams that were more cohesive. The researchers also found several important gender differences; female athletes perceived significantly more Training and Instruction, Democratic Behavior, Positive Feedback, and task cohesion than male counterparts. Males on the other hand perceived coaches significantly higher in Autocratic Behavior.

A similar study was conducted with baseball and softball players looking at the relationship between coaching leadership behaviors and cohesion (Shields et al., 1997). Using all three versions of the LSS, the researchers found the strongest relationship between perceived 
leadership behaviors and task cohesion. In regards to preferred leadership style, social cohesion contributed more to the leadership-cohesion relationship. The results of this study suggested that athletes preferred coaches that were successful in facilitating social cohesion in teams.

Turman (2003) conducted a qualitative study looking at the specific techniques and behaviors coaches used to try to motivate athletes and how they affected perceived team cohesion. Intuitively, coaching behaviors such as favoring athletes, ridiculing, and embarrassing team members negatively affected cohesion. Alternatively, coaches that bragged, used sarcasm, gave motivational speeches, gave team prayer and dedications, and utilized athlete-directed techniques all helped promote cohesion on their teams. This study highlighted both the negative and positive influence coaches' behaviors can have on team cohesion.

Jowett and Chaundy (2004) examined the coach-athlete relationship in relation to predicted team cohesion. Their study looked at specific coach-athlete relationship variables such as direct perceptions (i.e., how athletes thinks and feels about their coach) and meta-perceptions (i.e., relating to inferring the coach's own thoughts, feelings and behaviors). Results showed that these relationship variables were stronger predictors of task rather than social cohesion. The authors suggested that coach and athletes might find time is better spent on building task, rather than social cohesion, agreeing with the results of the study by Loughead et al. (2006). It was also suggested that coaches' perceptions of the coach-athlete relationship needed to be further examined.

Murray (2006) researched high school soccer and baseball players to examine the relationship between coaching behavior and cohesion. Similar to previous findings in the leadership-cohesion literature (e.g., Pease \& Kozub, 1994) Training and Instruction, Positive Feedback, and Social Support were also positively related to task and social cohesion. 
Interestingly, Democratic Behavior did not contribute significantly. Also, successful soccer teams were found to be more task cohesive and baseball teams less task cohesive. This is not surprising considering the incredible preparation, timing, and teamwork involved in being successful in the game of soccer.

Two recent studies of Iranian football (soccer) players focused on the relationship between coaching leadership style and team cohesion. Heydarinejad and Adman (2010) found that university league players reported that the majority $(88 \%)$ of coaches had a relationshiporiented leadership style. A significant, positive relationship was reported between combined (both task and social) leadership style and team cohesion. Task-oriented coaching style was not found to be significantly related to team cohesion. Interestingly, this result did not correlate with the findings of Jowett and Chaundy, who suggested that task cohesion on teams would be more beneficial to work on since coach-athlete variables such as direct perceptions were more highly related to team cohesion. In a similar study, Nezhad and Keshtan (2010) looked at the same relationship in professional footballers and found athletes' perceived that cohesion was positively related to coaches with high levels of Democratic Behavior, Training and Instruction, Positive Feedback, and Social Support (and low levels of Autocratic Behavior). It was also found that successful teams' coaches exhibited higher levels of Democratic and Social Support behavior. Overall, more successful football teams were found to be more cohesive.

\section{The Peer Cohesion-Leadership Relationship}

While there is a breadth of research focusing on the relationship between coaching style and cohesion, few studies have examined this relationship in the domain of athlete leadership. The only known study to specifically investigate the relationship between athlete leadership style and perceived cohesion examined this relationship with over 300 Canadian varsity and club 
athletes (Vincer \& Loughead, 2010). These athletes competed on a variety of interactive sports including ice hockey, indoor soccer, volleyball, and basketball. The researchers hypothesized that, similar to findings from coach leadership research (e.g., Gardner et al., 1996; Shields et al., 1997), the leadership behaviors of Training and Instruction, Positive Feedback, Social Support, and Democratic Behavior would all be positively related to all four dimensions of cohesion, while Autocratic Behavior would be negatively related to team cohesion. The authors came to these hypotheses because it was postulated that the results from coaching leadership research would remain consistent when looking at athlete leaders because one of the key purposes of leadership is to ensure that the teams' needs and demands are sufficiently met. The researchers obtained data from the athletes using the GEQ and a modified version of the LSS. The modified version of the LSS used in the study simply changed the item stems of "my coach" to "the athlete leader(s)" so the scale could be used in assessing athlete leadership. Overall, the researchers found that individual perceptions of Training and Instruction and Social Support positively influenced the four constructs of team cohesion. Furthermore, Autocratic Behavior was negatively associated with all four constructs. Democratic Behavior was only associated positively with the cohesion construct of ATG-T. The researchers identified a number of limitations in the study such as using a modified version of a scale (i.e., the LSS) that was originally developed to measure only coaching behaviors. The researchers suggested that a new scale focusing on athlete leadership style might need to be devised. Furthermore, the study was correlational, so no cause and effect could be determined. The researchers also reported low internal consistency values for the GEQ. However it was suggested that the low consistency values of the GEQ might be due to differences in the stage of group development for the various 
sport teams. An important limitation of this study is that it did not consider gender differences in the relationship between athlete leadership style and cohesion.

A review of the literature on the relationship between leadership behavior and cohesion produced a large number of studies on coach leadership style and cohesion (e.g., Heydarinejad \& Adman, 2010; Shields et al., 1997). However, as noted previously, little research has been conducted on the athlete leadership-cohesion relationship (e.g., Vincer \& Loughead, 2010). One potential reason why the literature on athlete leadership-cohesion relationship is so scarce is the difficulty in assessing the number and type of athlete leaders on a team. Currently, a modified version of the LSS (Loughead \& Hardy, 2005; Vincer \& Loughead, 2010) is the only way to assess athletes' perceived and preferred leadership behaviors of athlete leaders (as well as selfreported leadership behaviors of athlete leaders). In 2010, Horn, Glenn, and Campbell also used another modified version of the LSS and named it the Peer Leadership Scale for Sports (PLSS). The PLSS is equivalent to the original instrument except for changing the coaching stems "the coach on my team..." to athlete leader stems such as "the peer leader on my team..." Although the LSS was originally designed to assess coaching leadership style, leadership dispersion is a problematic variable since coaching leadership assessment normally involves just one head coach. Alternatively, there can be many types of athlete leaders on a single team, all serving different functions for the team.

It is clear that athlete leaders serve important and necessary roles on sport teams. These roles can be informal or formal, but all affect the non-leader players on the team. Research on the influence of these athletes' leadership behaviors on cohesion is scarce, and no known research has examined the way in which gender influences the peer leadership-cohesion relationship. It is essential for coaches, consultants, and athlete leaders to research and 
understand if gender differences exist in the peer leadership-cohesion relationship and if so what they may be. 


\section{References}

Beam, J.W., Serwatka, T.S., \& Wilson, W.J. (2004). Preferred leadership of NCAA Division I and II intercollegiate student-athletes. Journal of Sport Behavior, 27(1), 3-17.

Bird, A.M., \& Cripe, B.K. (1986). Psychology and sport behavior. St. Louis, Missouri: Times Mirror/Mosby.

Brawley, L.R., Carron, A. V., \& Widmeyer, W.N. (1987). Assessing the cohesion of teams: Validity of the Group Environment Questionnaire. Journal of Sport Psychology, 9, 275294.

Brawley, L.R., Carron, A. V., \& Widmeyer, W.N. (1993). The influence of the group and its cohesiveness on perceptions of group goal-related variables. Journal of Sport and Exercise Psychology, 15, 245-260.

Brawley, L.R., Carron, A.V., \& Widmeyer, W.N. (2002). The Group environment questionnaire test manual. Morgantown, WV: FIT.

Carron, A.V. (1982). Cohesiveness in sport groups: Interpretations and considerations. Journal of Sport Psychology, 4, 123-138.

Carron, A.V., \& Eys, M.A. (2012) Group dynamics in sport (4 $4^{\text {th }}$ ed.). Morgantown, WV: FIT.

Carron, A.V., \& Hausenblas, H.A. (1998). Group dynamics in sport (2 ${ }^{\text {nd }}$ ed.). Morgantown, WV: FIT.

Carron, A.V., Brawley, L.R., \& Widmeyer, W.N. (1985). The development of an instrument to assess cohesion in sport teams: The Group Environment Questionnaire. Journal of Sport Psychology, 7, 244-267. 
Carron, A.V., Brawley, L.R., \& Widmeyer,W.N. (1997). The measurement of cohesiveness in sport groups. In J.L. Duda (Ed.), Advancements in sport and exercise psychology measurements (pp. 213-226). Morgantown, WV: FIT.

Carron, A.V., Colman, M.M., Wheeler, J., \& Stevens, D. (2002). Cohesion and performance in sport: A Meta analysis. Journal of Sport \& Exercise Psychology, 24, 168-188.

Chelladurai, P. \& Carron, A.V. (1983). Athletic maturity and preferred leadership. Journal of Sport Psychology, 5, 371-380.

Chelladurai, P., \& Riemer, H. A. (1998). Measurement of leadership in sport. In J. L. Duda (Ed.), Advances in sport and exercise psychology measurement. Morgantown, WV: FIT.

Chelladurai, P., \& Saleh, S.D. (1978). Preferred leadership in sports. Canadian Journal of Applied Sport Sciences, 3, 85-92.

Chelladurai, P., \& Saleh, S.D. (1980). Dimensions of leader behavior in sports: Development of a leadership scale. Journal of Sport Psychology, 2, 34-45.

Dupuis, M., Bloom, G.A., \& Loughead, T.M. (2006). Team captains’ perceptions of athlete leadership. Journal of Sport Behavior, 29(1), 60-78.

Eagly, A.H., \& Johnson, B.T. (1990). Gender and leadership style: A meta-analysis. Psychological Bulletin, 108(2), 233-256.

Eys, M.A., Carron, A.V., Bray, S.R., \& Brawley, L.R. (2007). Item wording and internal consistency of a measure of cohesion: The group environment questionnaire. Journal of Sport \& Exercise Psychology, 29, 395-402.

Eys, M.A., Loughead, T.M., \& Hardy, J. (2007). Athlete leadership dispersion and satisfaction in interactive sport teams. Psychology of Sport and Exercise, 8, 281-296. 
Festinger, L., Schachter, S., \& Back, K. (1950). Social pressures in informal groups. New York, NY: Harper.

Fletcher, D., \& Hanton, S. (2003). Sources of organizational stress in elite sports performers. The Sport Psychologist, 17, 175-195.

Gardner, D.E., Shields, D.L.L., Bredemeier, B.J.L., \& Bostrom, A. (1996). The relationship between perceived coaching behaviors and team cohesion among baseball and softball players. The Sport Psychologist, 10, 367-381.

Gill, D. (1977). Cohesiveness and performance in sport groups. In D. Smith, \& M. Bar-Eli (Eds.), Essential readings in sport and exercise psychology (pp. 171-184). Champaign, IL: Human Kinetics.

Gill, D. (1986). Psychological dynamics of sport. Champaign, IL: Human Kinetics.

Glenn, S.D., \& Horn, T.S. (1993). Psychological and personal predictors of leadership behavior in female soccer athletes. Journal of Applied Sport Psychology, 5, 17-34.

Gould, D., Hodge, K., Peterson, K., \& Petlichkoff, L. (1987). Psychological foundations of coaching: Similarities and differences among intercollegiate wrestling coaches. The Sport Psychologist, 1987, 1, 293-308

Greenleaf, C., Gould, D., \& Dieffenbach, K. (2001). Factors influencing Olympic performance: Interviews with Atlanta and Nagano US Olympians. Journal of Applied Sport Psychology, 11, 154-184.

Hardy, A., Eys, M.A., \& Loughead, T.M. (2009). Does communication mediate the athlete leadership to cohesion relationship? International Journal of Sport Psychology, 39 (4), $329-345$. 
Heydarinejad, S., \& Adman, O. (2010). The relationship between coaching leadership styles and team cohesion in football teams of the Iranian university league. Studies in Physical Culture and Tourism, 17(4), 367-372.

Holmes, R.M., McNeil, M., \& Adorna, P. (2010). Student athletes' perceptions of formal and informal team leaders. Journal of Sport Behavior, 33(4), 442-465.

Horn, T.S., Glenn, S.D., \& Campbell, W. (2010). Perceived peer leadership behaviors: Links with adolescent female athletes' anxiety and goal orientation. Sport Science Review, 19(3-4), 239-263.

Jambor, E.A., \& Zhang, J.J. (1997). Investigating leadership, gender, and coaching level using the Revised Leadership for Sport Scale. Journal of Sport Behavior, 20(3), 313-321.

Jowett, S., \& Chaundy, V. (2004). An investigation into the impact of coach leadership and coach-athlete relationship on group cohesion. Group Dynamics: Theory, Research, and Practice, 8(4), 302-311.

Loughead, T.M., \& Hardy, J. (2005). An examination of coach and peer leader behaviors in sport. Psychology of Sport and Exercise, 6(3), 303-312.

Landers, D.M., \& Luschen, G. (1974). Team performance outcome and the cohesiveness of competitive coacting groups. In D. Smith, \& Bar-Eli, M. Essential readings in sport and exercise psychology (pp. 166-171). Champaign, IL: Human Kinetics.

Loughead, T.M., Hardy, J., \& Eys, M.A. (2006). The nature of athlete leadership. Journal of Sport Behavior, 29(2), 142-158.

Martens, R. (1987). Coaches guide to sport psychology. Champaign, IL: Human Kinetics. 
Martens, R., \& Peterson, J.A. (1971). Group cohesiveness as a determinant of success and member satisfaction in team performance. International Review of Sport Sociology, 6, 4971.

Martens, R., Landers, D.M., \& Loy, J.W. (1972). Sport cohesiveness questionnaire. Washington, D.C..: AAHPERD Publications.

Mikalachki, A. (1969). Group cohesion reconsidered. London, Ont: School of Business Administration, University of Western Ontario.

Mullen, B., \& Copper, C. (1994). The relation between group cohesiveness and performance: An Integration. Psychological Bulletin, 115(2), 210-227.

Murray, N.P. (2006). The differential effect of team cohesion and leadership behavior in high school sports. Individual Differences Research, 4(4), 216-225.

Neubert, M.J. (1999). Too much of a good thing or the more the merrier? Exploring the dispersion and gender composition of informal leadership in manufacturing teams. Small Group Research, 30(5), 635-646.

Nezhad, R.R., \& Keshtan, M.H. (2010). The coach's leadership styles team cohesion and team success in Iran football clubs professional league. International Journal of Fitness, 6(1), $53-61$.

Northouse, P. G. (2001). Leadership: Theory and practice \{2nd ed.). Thousand Oaks, CA: Sage.

Nunnally, J.C., \& Bernstein, I.H. (1994). Psychometric theory (3 ${ }^{\text {rd }}$ ed.). New York, NY: McGraw Hill.

Pease, D.G., \& Kozub, S. (1994). Perceived coaching behaviors and team cohesion in high school basketball teams. Journal of Sport \& Exercise Psychology: NASPSPA Abstracts, $16, \mathrm{~S} 93$. 
Price, M.S., \& Weiss, M.R. (2011). Peer leadership in sport: Relationships among personal characteristics, leader behaviors, and team outcomes. Journal of Applied Sport Psychology, 23, 49-64.

Sherman, C.A., Fuller, R., \& Speed, H.D. (2000). Gender comparisons of preferred coaching behaviors in Australian sports. Journal of Sport Behavior, 23(4), 389-406.

Shields, D.L.L., Gardner, D.E., Bredemeier, B.J.L., \& Bostrom, A. (1997). The relationship between leadership behaviors and group cohesion in team sports. The Journal of Psychology, 131(2), 196-210.

Turman, P.D. (2003). Coaches and cohesion: The Impact of coaching techniques on team cohesion in the small group sport setting. The Journal of Sport Behavior, 26(1), 86-104.

Vincer, D.J.E., \& Loughead, T.M. (2010). The relationship among athlete leadership behaviors and cohesion in team sports. The Sport Psychologist, 24, 448-467.

Westre, K.R., \& Weiss, M.R. (1991). The relationship between perceived coaching behaviors and group cohesion in high school football teams. The Sport Psychologist, 5, 41-54.

Williams, J.M., \& Hacker, C.M. (1982). Casual relationships among cohesion, satisfaction, and performance in women's intercollegiate field hockey teams. Journal of Sport Psychology, 4, 324-337.

Yukelson, D. (1997). Principles of effective team building interventions in sport: A direct services approach at Penn State University. Journal of Applied Sport Psychology, 9, 7396.

Yukelson, D., Weinberg, R., Richardson, P., \& Jackson, A. (1981). Interpersonal attractions and leadership within collegiate sport teams. The Journal of Sport Behavior, 6, 29-36. 
Zhang, J. J., Jensen, B. E., \& Mann, B. L. (1997). Modification and revision of the leadership scale for sport. Journal of Sport Behavior, 20(1), 105-122. 